TITLE:

\title{
Elasto-viscoplastic modeling of Osaka soft clay considering destructuration and its effect on the consolidation analysis of an embankment
}

\section{$\operatorname{AUTHOR}(\mathrm{S}):$}

Mirjalili, M.; Kimoto, S.; Oka, F.; Higo, Y.

\section{CITATION:}

Mirjalili, M....[et al]. Elasto-visco plastic modeling of Osaka soft clay considering destructuration and its effect on the consolidation analysis of an embankment. Geomechanics and Geoengineering 2011, 6(2): 69-89

\section{ISSUE DATE:}

2011-06

URL:

http://hdl.handle.net/2433/156793

\section{RIGHT:}

(c) 2011 Taylor \& Francis; This is not the published version. Please cite only the published version.; この論文は出版社版でありません。引用の 際には出版社版をご確認ご利用ください。 


\title{
Elasto-viscoplastic modeling of Osaka soft clay considering destructuration and its effect on the consolidation analysis of an embankment
}

\author{
M. Mirjalili, S. Kimoto, F. Oka*, and Y. Higo \\ Department of Civil and Earth Resources Engineering \\ Kyoto University, Kyotoudaigaku-katsura 4, Nishikyo-ku, Kyoto, 615-8540, Japan \\ *Corresponding author: oka.fusao.2s@kyoto-u.ac.jp
}

\begin{abstract}
:
A numerical modeling of Osaka soft clay was carried out using an elasto-viscoplastic constitutive model. The effect of destructuration, demonstrated by the shrinkage of the yield and the overconsolidation boundary surfaces and the strain-dependent elastic shear modulus, were studied through a comparison of the simulations with the experimental results of undrained triaxial compression tests. Although consideration of the structural degradation in the modeling of soft soil behavior leads to a substantial improvement, in terms of strain softening and postpeak responses, the strain-dependent shear modulus was introduced to reproduce more precise behavior, particularly before the peak stress. In order to evaluate the effect of these two aspects in a boundary value problem, a two-dimensional consolidation analysis of an embankment construction on a soft clay layer was conducted for three different cases. The deformations and the excess pore pressure responses for each case were presented and discussed. The strain localization, the consequent large ground displacement, and the temporary increase in pore pressure during the consolidation were observed in the cases with structural degradation. Considering the strain-dependent shear modulus, however, larger strain localization and displacement were predicted even in the early stages of loading.
\end{abstract}

Keywords: Soft clay; Elasto-viscoplastic model; Structural degradation; Embankment; Straindependent shear modulus 


\section{Introduction}

Soft clay specimens have shown complex behavior during shearing, which can be associated with the collapse of the soil structure and microstructural changes. The structure of natural soil consists of two components, namely, the fabric and the bonding between particles (Burland 1990). The term 'destructuration' is often used to describe the progressive damage to the bonding between soil particles during plastic straining. In many natural soft clays, the presence of interparticle bonding is demonstrated by sensitivity. The sensitivity of clay is defined as the ratio of its undisturbed strength to its remolded strength (Terzaghi 1944). The sensitivity may range from about 4 , for sensitive clays, to values of over 100 , for so-called extra-sensitive or quick clays. In fact, most clays, except for those which have been heavily overconsolidated, lose a portion of their original strength after remolding. For Osaka soft clay, sensitivity levels of 4 to 10 are quite common, which indicates the high sensitivity of this type of clay. In some areas, however, larger values have been reported (e.g., Adachi et al. 1995, KG-NET 2007).

Certain types of unstable behavior, such as the anomalous pore pressure response after the completion of loading and secondary creep caused by the destructuration in sensitive clays, have been reported by many researchers, e.g., Mesri and Choi (1979), Mitchell (1986), Lavallee et al. (1992), etc. Predictions of these phenomena through the viscoplastic constitutive models have been conducted over the last few decades, e.g., Zienkiewicz et al. ( 1975), Sekiguchi (1977), Nova (1982), Adachi and Oka (1982), Yin and Graham (1999), etc. Oka et al. (1991) have introduced the variation in the viscoplastic parameter into the original elasto-viscoplastic constitutive model, proposed by Adachi and Oka (1982), to represent the structural breakdown of clay. However, it was not able to successfully reproduce the field anomalous soil behavior during long-term consolidation. Later on, Kimoto and Oka (2005) improved the elasto-viscoplastic constitutive model for use in predicting the unstable behavior during consolidation. In their proposed model, structural changes are expressed as strain softening, with respect to the accumulation of viscoplastic strain, so that the model can describe the instability not only around the failure stress, but also during compressive deformation. A validation of the proposed model has been performed by applying it to simulate various laboratory and field tests in addition to practical problems (e.g., Kimoto and Oka 2005, Oka et al. 2008, Karim and Oka 2010). Although giving consideration to the effect of structural degradation on strain softening and post-peak responses has helped to improve reproductions of the stress-strain behavior of soft clays, the 
reproduced results, particularly in the small strain range, have often differed from the laboratory test data. Hence, the strain dependency of the elastic shear modulus is employed to overcome this inadequacy in the modeling of soft clays.

It is well known that the deformation characteristics of soils, particularly the elastic shear modulus, are non-linear due to the microstructural changes that occur during loading. The shear modulus at small strain levels is often expressed as the function of the void ratio and the effective confining stress through the several empirical equations from the laboratory tests (Ishihara 1996). Consideration of the effective confining pressure has been made by normalizing the shear modulus through a power function of the mean effective stress. For large stains, however, the strain dependency of the shear modulus should also be taken into account. An evaluation of the variation in the shear modulus in the experiments reveals the significant reduction in the shear modulus when strain increases. Several empirical equations have been proposed for the strain-dependent shear modulus of geomaterials (e.g., Kovacs et al. 1971, Hardin and Drnevich 1972, Seed et al. 1986, etc.). For soft clays, Ogisako et al. (2007) have shown the normalized elastic shear modulus reduction function based on the viscoplastic shear strain and have proposed a hyperbolic equation for that expression in the elasto-viscoplastic constitutive model.

The aim of this paper is to study the effect of destructuration on the elasto-viscoplastic modeling of Osaka soft clay. In order to predict the soil behavior, using the elasto-viscoplastic model proposed by Kimoto and Oka (2005), the model parameters were firstly determined based on the laboratory test data. Then, element test simulations were performed considering the destructuration parameters, i.e., structural degradation and the strain-dependent shear modulus. Comparisons were made through the stress-strain relations and the stress paths under undrained triaxial compression conditions. The influences of the structural degradation and the straindependent shear modulus were particularly studied in a two-dimensional consolidation analysis of an embankment construction on a layer of Osaka soft clay. Several numerical simulations have been done in order to properly study the effect of each aspect of destructuration.

\section{Elasto-viscoplastic constitutive model}

As mentioned earlier, we have adopted the elasto-viscoplastic constitutive model proposed by Kimoto and Oka (2005). The model is an extension of the rate-dependent model for water- 
saturated clay, firstly proposed by Adachi and Oka (1982), which combines the Cam-clay model (Roscoe, Schofield and Thurairajah 1963) and Perzyna's (1963) overstress type of viscoplasticity for the elasto-viscoplastic formulation. Kimoto and Oka (2005) improved the original model by Adachi and Oka (1982) in order to overcome the structural degradation of the soil skeleton, considering the shrinkage of both the overconsolidation boundary surface and the static yield surface with respect to the accumulation of viscoplastic strain. In this section, the features of the model are described as can be found in Kimoto and Oka (2005). However, the model is modified here in two ways, namely, the variation in the stress ratio at failure by Lode's angle and the introduction of a new definition for the dilatancy coefficient.

In the adopted constitutive model, Terzaghi's effective stress for water-saturated soil is used as

$$
\sigma_{i j}=\sigma_{i j}^{\prime}+U_{w} \delta_{i j}
$$

where $\sigma_{i j}$ is the total stress tensor, $\sigma_{i j}^{\prime}$ is the effective stress tensor, $U_{w}$ is the pore water pressure, and $\delta_{i j}$ is Kronecker's delta. In addition, total strain rate tensor $\dot{\varepsilon}_{i j}$ is assumed to be divided into two parts, namely,

$$
\dot{\varepsilon}_{i j}=\dot{\varepsilon}_{i j}^{e}+\dot{\varepsilon}_{i j}^{v p}
$$

where $\dot{\varepsilon}_{i j}^{e}$ denotes the elastic strain rate tensor and $\dot{\varepsilon}_{i j}^{v p}$ is the viscoplastic strain rate tensor. The elastic strain rate tensor can be expressed as

$$
\dot{\varepsilon}_{i j}^{e}=\frac{1}{2 G} \dot{S}_{i j}+\frac{\kappa}{3\left(1+e_{0}\right)} \frac{\dot{\sigma}_{m}^{\prime}}{\sigma_{m}^{\prime}} \delta_{i j}
$$

in which $G$ is the elastic shear modulus, $S_{i j}$ is the deviatoric stress tensor $\left(S_{i j}=\sigma_{i j}^{\prime}-\sigma_{m}^{\prime} \delta_{i j}\right), \sigma_{m}^{\prime}$ is the mean effective stress, and the superimposed dot denotes the time differentiation. $\kappa$ is the swelling index and $e_{0}$ is the initial void ratio. The modification of elastic shear modulus $G$ will be presented in the next section.

An overconsolidation boundary surface is assumed to delineate the normally consolidated (NC) region and the overconsolidated (OC) region as

$$
f_{b}=\bar{\eta}_{(0)}^{*}+M_{m}^{*} \ln \left(\sigma_{m}^{\prime} / \sigma_{m b}^{\prime}\right)=0
$$


where $f_{b}<0$ indicates the overconsolidated region and $f_{b} \geq 0$ shows the normally consolidated region.

In Equation (4), $\bar{\eta}_{(0)}^{*}$ is the relative stress ratio defined by

$$
\bar{\eta}_{(0)}^{*}=\sqrt{\left(\eta_{i j}^{*}-\eta_{i j(0)}^{*}\right)\left(\eta_{i j}^{*}-\eta_{i j(0)}^{*}\right)}
$$

in which subscript (0) denotes the initial state before deformation and $\eta_{i j}^{*}$ is the stress ratio tensor. $\sigma_{m b}^{\prime}$ controls the size of the OC boundary surface. $M_{m}^{*}$ is the value of $\eta^{*}=\sqrt{\eta_{i j}^{*} \eta_{i j}^{*}}$ when the volumetric strain increment changes from compression to swelling. In order to include MohrCoulomb's failure criterion with zero cohesion, stress ratio $M_{m}^{*}$ is considered to be a function of Lode's angle $\theta$ given by

$$
\begin{gathered}
\theta=\frac{1}{3} \cos ^{-1}\left[\frac{3 \sqrt{3}}{2} \frac{J_{3}}{J_{2}^{3 / 2}}\right] \\
M_{m}^{*}(\theta)=\frac{6 \sqrt{2} \sin \phi}{(3+3 \sin \phi) \sin \theta+\sqrt{3}(3-\sin \phi) \cos \theta}
\end{gathered}
$$

where $J_{2}$ and $J_{3}$ are the second and the third invariants of the deviatoric stress tensor, respectively, and $\phi$ is the internal frictional angle. Lode's angle varies in the range of $0 \leq \theta \leq \pi / 3$, where $\theta=0$ represents the triaxial compression mode and the maximum value shows the extension mode of loading under triaxial conditions. In Equation (7), by taking $\theta=0$, the stress ratio at triaxial compression $M_{m c}^{*}$ can be obtained as

$$
M_{m c}^{*}=\sqrt{\frac{2}{3}} \frac{6 \sin \phi}{3-\sin \phi}
$$

To describe the structural degradation of clay, strain softening with the accumulated viscoplastic strain is introduced in addition to strain hardening with the viscoplastic volumetric strain as

$$
\sigma_{m b}^{\prime}=\sigma_{m a}^{\prime} \exp \left(\frac{1+e_{0}}{\lambda-\kappa} \varepsilon_{v}^{v p}\right)
$$

where $\sigma_{m a}^{\prime}$ is assumed to decrease with an increase in viscoplastic strain with

$$
\sigma_{m a}^{\prime}=\sigma_{m a f}^{\prime}+\left(\sigma_{m a i}^{\prime}-\sigma_{m a f}^{\prime}\right) \exp \left(-\beta z^{h}\right)
$$


in which $z$ is the accumulation of the second invariant of the viscoplastic strain rate given by

$$
z=\int_{0}^{t} \dot{z} d t ; \quad \dot{z}=\sqrt{\dot{\varepsilon}_{i j}^{v p} \dot{\varepsilon}_{i j}^{v p}}
$$

In Equation (10), $\sigma_{m a i}^{\prime}$ and $\sigma_{m a f}^{\prime}$ are the initial and the final values for $\sigma_{m a}^{\prime}$, respectively. $\beta$ is a parameter that stands for the changing rate of $\sigma_{m a}^{\prime}$, while the proportion of $n=\sigma_{m a f}^{\prime} / \sigma_{m a i}^{\prime}$ provides the degree of possible collapse of the soil structure at the initial state. $h$ is an additional degradation parameter with a non-negative value that controls the rate of degradation of the soil skeleton. In this study, the value of this parameter is assumed as $h=1$.

In the following, static yield function $f_{y}$ has been proposed to explain the mechanical behavior of clay at its static equilibrium state as

$$
f_{y}=\bar{\eta}_{(0)}^{*}+\tilde{M}^{*} \ln \left(\sigma_{m}^{\prime} / \sigma_{m y}^{\prime(s)}\right)=0
$$

where $\sigma_{m y}^{(s)}$ denotes the static hardening parameter.

Static equilibrium state $f_{y}=0$ refers to the case when no viscoplastic deformation occurs, which can only be reached after an infinite time. Incorporating the strain softening for the structural degradation, the hardening rule of $\sigma_{m y}^{\prime(s)}$ can be expressed as

$$
\sigma_{m y}^{(s)}=\frac{\left\{\sigma_{m a f}^{\prime}+\left(\sigma_{m a i}^{\prime}-\sigma_{m a f}^{\prime}\right) \exp (-\beta z)\right\}}{\sigma_{m a i}^{\prime}} \sigma_{m y i}^{(s)} \exp \left(\frac{1+e_{0}}{\lambda-\kappa} \varepsilon_{v}^{v p}\right)
$$

In the same manner as for the static yield function, viscoplastic potential function $f_{p}$ is given by

$$
f_{p}=\bar{\eta}_{(0)}^{*}+\tilde{M}^{*} \ln \left(\sigma_{m}^{\prime} / \sigma_{m p}^{\prime}\right)=0
$$

where dilatancy coefficient $\tilde{M}^{*}$ is defined separately for the overconsolidated region (OC) and the normally consolidated region (NC). In the original definition by Kimoto and Oka (2005), $\tilde{M}^{*}$ is given by 


$$
\tilde{M}^{*}= \begin{cases}M_{m}^{*}(\theta) & : \text { NC region } \\ -\frac{\sqrt{\eta_{i j}^{*} \eta_{i j}^{*}}}{\ln \left(\sigma_{m}^{\prime} / \sigma_{m c}^{\prime}\right)} & : \text { OC region }\end{cases}
$$

in which $\sigma_{m c}^{\prime}=\sigma_{m b}^{\prime}$ for isotropic consolidation. In general, it can be expressed as

$$
\sigma_{m c}^{\prime}=\sigma_{m b}^{\prime} \exp \left(\frac{\sqrt{\eta_{i j(0)}^{*} \eta_{i j(0)}^{*}}}{M_{m}^{*}(\theta)}\right)
$$

According to the above definition, the value of dilatancy coefficient $\tilde{M}^{*}$ becomes zero when the stress path coincides with the mean effective stress axis during cyclic loading. Therefore, a new definition for $\tilde{M}^{*}$ (Kimoto et al. 2007) is introduced here as

$$
\tilde{M}^{*}= \begin{cases}M_{m}^{*}(\theta) & : \text { NC region } \\ \left(\sigma_{m}^{*} / \sigma_{m b}^{\prime}\right) M_{m}^{*}(\theta) & : \text { OC region }\end{cases}
$$

where $\sigma_{m}^{*}$ denotes the mean effective stress at the intersection of the surface, which has the same shape as $f_{b}$, and is given by

$$
\sigma_{m}^{*}=\sigma_{m}^{\prime} \exp \left(\frac{\bar{\eta}_{(0)}^{*}}{M_{m}^{*}(\theta)}\right)
$$

The overconsolidation boundary surface, the static yield function, and the viscoplastic potential function are illustrated for isotropically consolidated soil in Figure $1 . \sigma_{m b}^{\prime}$ and $\sigma_{m y}^{\prime(s)}$ change with the structural degradation of the soil skeleton, namely, the viscoplastic strain accumulation. This leads to the gradual shrinkage of the overconsolidation boundary surface as well as the static yield surface, in both the overconsolidated region and the normally consolidated region.

Based on the overstress type of viscoplastic theory first adopted by Perzyna (1963), viscoplastic strain rate tensor $\dot{\varepsilon}_{i j}^{v p}$ is defined as

$$
\begin{gathered}
\dot{\varepsilon}_{i j}^{v p}=C_{i j k l}\left\langle\Phi\left(f_{y}\right)\right\rangle \frac{\partial f_{p}}{\partial \sigma_{k l}^{\prime}} \\
\left\langle\Phi\left(f_{y}\right)\right\rangle= \begin{cases}\Phi\left(f_{y}\right) & : f_{y}>0 \\
0 & : f_{y} \leq 0\end{cases}
\end{gathered}
$$




$$
C_{i j k l}=a \delta_{i j} \delta_{k l}+b\left(\delta_{i k} \delta_{j l}+\delta_{i l} \delta_{j k}\right)
$$

where \langle\rangle are Macaulay's brackets, $\Phi\left(f_{y}\right)$ is the rate-sensitive material function, and $C_{i j k l}$ is a fourth order isotropic tensor. $a$ and $b$ in Equation (21) are the viscoplastic parameters. $\Phi\left(f_{y}\right)$ is determined from the experimental correlation proposed by Adachi and Oka (1982) and Kimoto and Oka (2005) as

$$
\Phi\left(f_{y}\right)=\sigma_{m}^{\prime} \exp \left\{m^{\prime}\left(\bar{\eta}_{(0)}^{*}+\tilde{M}^{*} \ln \frac{\sigma_{m}^{\prime}}{\sigma_{m b}^{\prime}}\right)\right\}
$$

in which $m^{\prime}$ is the viscoplastic parameter.

Deviatoric viscoplastic strain rate $\dot{e}_{i j}^{v p}$ and volumetric viscoplastic strain rate $\dot{\varepsilon}_{i j}^{v p}$ can be expressed as

$$
\begin{gathered}
\dot{e}_{i j}^{v p}=C_{1} \exp \left\{m^{\prime}\left(\bar{\eta}_{(0)}^{*}+\tilde{M}^{*} \ln \frac{\sigma_{m}^{\prime}}{\sigma_{m b}^{\prime}}\right)\right\} \frac{\eta_{i j}^{*}-\eta_{i j(0)}^{*}}{\bar{\eta}^{*}} \\
\dot{\varepsilon}_{k k}^{v p}=C_{2} \exp \left\{m^{\prime}\left(\bar{\eta}_{(0)}^{*}+\tilde{M}^{*} \ln \frac{\sigma_{m}^{\prime}}{\sigma_{m b}^{\prime}}\right)\right\}\left\{\tilde{M}^{*}-\frac{\eta_{m n}^{*}\left(\eta_{m n}^{*}-\eta_{m n(0)}^{*}\right)}{\bar{\eta}^{*}}\right\}
\end{gathered}
$$

where $C_{1}=2 b$ and $C_{2}=3 a+2 b$ are the viscoplastic parameters for the deviatoric and the volumetric strain components, respectively.

\section{Strain-dependent elastic shear modulus}

The non-linearity of soil stiffness has been studied extensively on materials such as sands, clays, and gravel, and has been summarized well by Ishihara (1996). For cohesive soils, several empirical equations have been proposed by considering the dependency of the shear modulus on the effective confining stress (Kokusho et al. 1982). In the original configuration by Kimoto and Oka (2005), the change in the elastic shear modulus of the elasto-viscoplastic model is given by the square root function of the normalized mean effective stress as

$$
G=G_{0} \sqrt{\frac{\sigma_{m}^{\prime}}{\sigma_{m 0}^{\prime}}}
$$

in which $G_{0}$ is the value for $G$ when $\sigma_{m}^{\prime}=\sigma_{m 0}^{\prime}$. 
Equation (25) considers only the effect of the confining pressure, which can accurately approximate the variation in shear modulus at very small levels of strain. In regions with large levels of strain, however, as demonstrated by the experimental results, the strain dependency of the shear modulus should be considered as well. Various empirical formulations have been provided from the laboratory test results to express the strain dependency of the shear modulus (e.g., Hardin and Drnevich 1972, Wang and Kuwano 1999). Ogisako et al. (2007) have introduced a normalized shear modulus reduction function based on the viscoplastic shear strain in soft clay specimens and have proposed a hyperbolic equation for that expression, namely,

$$
G=G_{0} \frac{1}{\left(1+\alpha\left(\gamma^{v p}\right)^{r}\right)}
$$

where $\alpha$ and $r$ are the experimental constants, which can be defined from the laboratory test results, and $\gamma^{v p}$ is the accumulated viscoplastic shear strain given by an accumulation of the viscoplastic deviatoric strain rate as

$$
\gamma^{v p}=\int \sqrt{d e_{i j}^{v p} d e_{i j}^{v p}}
$$

In this study, based on the experimental results, $r=0.4$ is chosen. Therefore, the final formulation for the variation in shear modulus can be incorporated as

$$
G=G_{0} \frac{1}{\left(1+\alpha\left(\gamma^{v p}\right)^{0.4}\right)} \sqrt{\frac{\sigma_{m}^{\prime}}{\sigma_{m 0}^{\prime}}}
$$

in which $\alpha$ is the strain-dependent parameter.

\section{Numerical modeling of Osaka soft clay}

The numerical modeling of Osaka soft clay specimens has been conducted using the described elasto-viscoplastic model. Material parameters have been determined by laboratory tests using natural samples. The sampling procedures were performed as part of a geotechnical investigation of a super-levee construction project along the Yodo River in Torishima, Osaka City, Japan. A super-levee is a river embankment with a broad width, which can withstand even overflow, so that destruction by a dike break and its resultant flooding can be prevented. In addition, it is expected to have more resistibility against earthquakes and the consequent damage they cause. Considering the special issues involved in the construction of such a massive earth structure on 
soft clay deposits, attempts should be made to predict the consolidation behavior of the soft clay as accurately as possible.

Geotechnical investigations have been performed through the drilling of two boreholes, which reach down to about $40 \mathrm{~m}$ below ground level. Standard penetration tests (SPT) and undisturbed tube samplings $(\Phi=75 \mathrm{~mm})$ in various layers have been performed. According to the boring results, the subsurface strata were composed of alluvial sand and soft clay layers overlying a diluvium dense gravel layer and a rather stiff clay layer at a depth of about $35 \mathrm{~m}$. The cross section of the subsurface layers is schematically illustrated in Figure 2. B1 represents the topsoil material with a thickness of about $2.25 \mathrm{~m}$, As2 is the upper alluvial sand layer with a thickness of approximately $8.5 \mathrm{~m}$, Ac2 is the alluvial soft clay layer with a thickness of $12 \mathrm{~m}$, As1 is the lower alluvial sand layer with a thickness of $5.5 \mathrm{~m}$, and Ac1 is the alluvial clay deposit. Dg and Dc indicate the diluvium sandy gravel and rather stiff clay deposits, respectively.

Laboratory tests were conducted on the clay specimens obtained from the Ac2 layer, including undrained triaxial compression tests with different strain rates, and consolidation tests with different loading methods, namely, the constant rate of loading (CRL) and the standard incremental loading (STD) methods. The triaxial tests on the soft clay samples were conducted at two different strain rates, namely, $0.05 \% / \mathrm{min}$ and $0.005 \% / \mathrm{min}$, and at three levels of confining pressure equal to 100,200 , and $400 \mathrm{kPa}$. For the Ac2 layer in Torishima, the value of sensitivity has been reported as $6 \sim 8$ (KG-NET 2007), which indicates the high sensitivity of the Osaka soft clay in this district. In order to predict the triaxial behavior of soft clay, elasto-viscoplastic model parameters have been determined from the laboratory test results following the proposed method by Kimoto and Oka (2005), as well as other characteristic parameters. Viscoplastic parameter $m^{\prime}$ is determined from undrained triaxial compression tests conducted at different strain rates. By having $m^{\prime}$, the other viscoplastic parameters, $C_{1}$ and $C_{2}$, are obtained from Equations (23) and (24) in the triaxial stress state. The representative material parameters of the Ac2 layer are listed in Table 1. It is seen that the soft clay layer was divided into three individual sub-layers based on the soil properties. The stress-strain relations and the stress paths were used to evaluate the aspects of the destructuration in the constitutive modeling. 


\subsection{Modeling of soft clay considering structural degradation}

As the first stage, the behavior of the soft clay specimens obtained from the Ac2 layer were simulated using the representative material parameters listed in Table 1, which were determined based on the triaxial test results. Comparisons were made with the experimental results through the stress-strain relations and the stress paths. The effect of structural parameters $n$ and $\beta$ on the stress-strain relations and the stress paths have been shown by Kimoto and Oka (2005) as softening behavior after the peak stress point, in which the larger structural parameter, $\beta$, promotes the rapid degradation of the shear strength. Nonetheless, the behavior before the peak stress point does not change with the structural parameters and it remains similar to that of the case in which no structural degradation is considered $(\beta=0)$.

Figures 3 and 4 present the experimental results and the corresponding simulated results by the elasto-viscoplastic model, where the symbols show the experimental values and the solid lines represent the relevant simulated results. The stress-strain relations of the testing samples and the predicted results are presented in Figure 3. The results demonstrate quite a good tendency, in terms of strain softening and post-peak responses. However, considering the behavior around the peak stress point, the simulated results show smaller strain at the same shear stress level. This implies a larger shear modulus in the predicted results, which leads to a smaller accumulated deformation.

The simulated stress paths for the clay specimens under different levels of confining pressure, illustrated in Figure 4, follow the corresponding experimental results, although the initial part of the stress path curve in some cases does not agree with the experimental values. The simulations indicate the elastic behavior at the initial part of the stress paths in contrast to the experimental data. In order to improve the predicted results, the inequality of the viscoplastic parameter for deviatoric strain component $C_{1}$ and the viscoplastic parameter for volumetric strain component $C_{2}$ was considered by taking different values for $C_{2}$, as $C_{2} \geq C_{1}$. Nonetheless, the effect of this consideration was insignificant. The dissimilarity of the stress paths between the simulation and the experiments can be attributed to the influence of the sampling process and the consequent disturbance to the structured soil behavior, which results in less elasticity in the earlier stages of shearing in the laboratory tests. Furthermore, the pore water pressure in the tests, which is measured by means of a pressure sensor connected to the top and the bottom of the 
specimen, represents an average value of the pore water pressure within the entire sample. However, the simulation results, obtained by the integration of the constitutive equations, represent the one-point response in which the size or the boundary effect has been disregarded.

\subsection{Modeling of soft clay considering structural degradation and strain-dependent shear modulus}

In order to improve the predicted results, the strain-dependent elastic shear modulus was taken into consideration in addition to structural degradation. Giving consideration to the effect of the strain dependency of the shear modulus in the modeling changes the values of the structural parameter. The strain-dependent parameter $\alpha$, and the modified values for structural parameter $\beta$ are presented in Table 2 .

Figure 5 indicates the stress-strain relations of the predicted results beside the experimental data, while the stress paths for both cases are presented in Figure 6. As mentioned above, the symbols in these figures represent the experimental data from laboratory tests and the solid lines show the corresponding predicted values when using the elasto-viscoplastic constitutive model. Applying the modified values for $\beta$ and the strain-dependent shear modulus leads to more accurately predicted results. Although giving consideration to strain-dependent shear modulus $G$ leads to an enormous improvement in the predictions of the stress-strain relations, particularly around the peak stress points, its effect on the stress paths under triaxial test conditions is insignificant. The predicted results emphasize the capability of the elasto-viscoplastic model to reproduce the sensitive soil behavior through the structural degradation parameters, of which a more accurate response is achieved by considering the strain dependency of the shear modulus.

\section{Consolidation analysis of an embankment construction on soft clay}

The effects of these two factors, structural degradation and the strain-dependent shear modulus, have been studied in the context of a typical geotechnical problem, namely, a two-dimensional embankment construction. The finite element consolidation analysis of an embankment on a soft clay foundation was performed for three cases. All cases assume the same initial conditions. In Case 1, both destructuration aspects were ignored by making $\beta$ and $\alpha$ equal to zero (no structural degradation). In Case 2, the effect of structural degradation was considered, while the original shear modulus formulation, Equation (25), was used. In Case 3, the effect of the strain-dependent shear modulus was considered in the simulation by applying Equation (28) and the modified 
values for structural parameter $\beta$. The overall features in each case of the finite element analysis are summarized in Table 3. Comparisons have been made among the results of these cases to evaluate the influence under plane-strain conditions.

\subsection{Problem description}

The consolidation analysis of the Osaka soft clay foundation subjected to embankment construction was performed using the finite element method. The geometry and the finite element mesh of the problem are presented in Figure 7, where a typical embankment with a height of $3.2 \mathrm{~m}$ and a slope of 1:2, was constructed on a soft clay foundation with a thickness of $10 \mathrm{~m}$ and characterized by the parameters of Osaka soft clay. As shown in Figure 7, the embankment layers were properly modeled in the finite element mesh so the stiffness and the consolidation of the embankment layers could be considered in the simulation in addition to the embankment loading. Due to symmetry, only half of the embankment was represented in the finite element mesh. The size of the modeled domain was determined so that the boundary effects would be negligible. A fully saturated condition was assumed, in which only the boundary located at the top was permeable. The displacement boundary at the bottom of the domain, which is regarded as the base ground, was fixed in both vertical and horizontal directions, while the right- and the left-hand side boundaries were fixed only in the horizontal direction. Mesh sensitivity studies were done to confirm that the mesh was dense enough to produce converging results.

The elasto-viscoplastic material parameters of the Ac2-M layer were applied for the soft ground layer, while the elastic behavior was adopted for the embankment layers assumed to be made of granular fill. Table 4 gives the material parameters, which were used in the finite element analysis.

\subsection{Finite element formulation}

In the numerical analysis, the finite element method for two-phase mixtures, based on the finite deformation theory, was adopted with the objective Jaumann rate of Cauchy stress for the weak form of the equilibrium equation (Oka et al. 2002, Kimoto et al. 2004). Concerning the finite deformation framework, strain rate tensor $\dot{\varepsilon}_{i j}$ in the previous section is replaced by stretching (or 
the rate of deformation) tensor $D_{i j}$. An eight-node quadrilateral element with a reduced Gaussian four-point integration was employed for the displacement. The pore water pressure was defined at the four corner nodes of the elements. A Biot's type of two-phase mixture theory was used with a velocity-pore pressure formulation. The finite element formulation, based on the updated Lagrangian method, is explained in Appendix A, including the discretization of the equilibrium equation following the continuity equation.

\subsection{Construction procedure and loading profile}

The linearized construction sequence of the embankment is schematically shown in Figure 8 . The rate of loading was simulated by the successive addition of elements corresponding to each stage of embankment construction. For a particular construction stage, the elements to be constructed were added and given a constitutive model appropriate to the material behavior during placing. The nodal forces due to the self-weight body forces of the constructed material were calculated and applied to the corresponding nodes. The global stiffness matrix and all the other boundary conditions were assembled for the stage, and the FEM analysis was implemented. Before applying the next stage, the displacements of any nodes, which are only connected to the constructed elements, were zeroed (Potts and Zdravkovic 1999). As shown in Figure 8, it was assumed that the embankment would be constructed in four layers within 40 consecutive days. A consolidation analysis was performed until 1000 days after the end of the construction.

\section{Numerical analysis results and discussion}

\subsection{Vertical displacements}

The predicted results for the vertical displacements at the ground level due to the construction of the embankment are presented in Figure 9 for all three cases on various days. The settlements at the ground level are shown corresponding to each construction stage and consolidation after the end of construction. All cases show a trough-shaped ground settlement beneath the embankment with a surface heave around the toe of the embankment. Despite the increases in ground settlement beneath the embankment, during and after construction, the surface heave around the 
toe decreases during consolidation. The maximum settlement at each construction stage occurs at the node which is located just beneath the centerline of the embankment.

All the cases, i.e., Case 1 with no structural degradation, Case 2 with structural degradation, and Case 3 with structural degradation and strain-dependent shear modulus, demonstrate the same general features in terms of ground settlement, although the settlement values are different for each case. Regarding the settlement at the embankment centerline after 40 days, Cases 1 and 2 have almost similar settlements with a value of $2.17 \mathrm{~cm}$. Thereafter, however, during consolidation, the strain rate in Case 2 increases (due to the softening in the soft clay layer) and leads to a larger displacement, i.e., $7.67 \mathrm{~cm}$, at the embankment centerline after 1000 days versus a displacement of $4.65 \mathrm{~cm}$ in Case 1 at the same time. In Case 3, where the effect of the straindependent shear modulus has been incorporated, the settlement becomes significantly large not only during consolidation, but also during the construction of the embankment. The surface settlement that develops at the embankment centerline after the final construction step, after 40 days, is $2.4 \mathrm{~cm}$ in Case 3 which increases up to $8.9 \mathrm{~cm}$ after 1000 days during consolidation. Figure 10 shows the vertical ground displacements at the embankment centerline versus time for all three cases. An evaluation of the development of settlement over time for all three cases clearly indicates the effect of both the structural degradation and the strain dependency of the shear modulus considerations.

The vertical ground displacements versus time at the toe of the embankment, $9.5 \mathrm{~m}$ from the embankment centerline, are presented in Figure 11 for the different cases. The vertical displacement at the toe firstly exhibits heaving when the embankment construction is in progress and reaches its maximum value immediately after the end of construction. Then, the settlement increases with time during consolidation. As illustrated in Figure 11, the three cases demonstrate almost the same trend in vertical displacement profiles at the toe of the embankment. By considering the structural degradation, however, a larger displacement is observed in Case 2 than in Case 1. In Case 3, the displacements during and after construction are somewhat larger than those in the other cases. Later on, after about 500 days, the displacement rate decreases gradually and becomes smaller than the values for Case 2 . 


\subsection{Lateral displacements}

The variations in lateral displacement along the depth beneath the toe of the embankment are shown in Figure 12. As the displacements of the nodes located at the bottom of the model were fixed in both directions, the lateral displacement at a depth of $10 \mathrm{~m}$ is zero. The lateral displacement at the toe of the embankment develops during the construction and reaches the maximum positive value at a depth of $3.0 \mathrm{~m}$ upon completion of loading. Thereafter, it decreases with time as consolidation occurs and achieves negative values after 1000 days of consolidation at the same depth. When comparing the horizontal displacement at the toe of the embankment after the end of construction, after 40 days, Cases 1 and 2 present nearly identical lateral displacements with a value of $1.22 \mathrm{~cm}$ at a depth of $3.0 \mathrm{~m}$, as shown in Figures 12(a) and (b). On the other hand, Case 3, which considers the strain-dependent shear modulus, shows a slightly larger lateral displacement with a value of $1.35 \mathrm{~cm}$ at the same depth, as shown in Figure 12(c). The values of the lateral displacement after 1000 days at a depth of $3.0 \mathrm{~m}$ are $-1.62 \mathrm{~cm}$ for Case 1 , $-1.35 \mathrm{~cm}$ for Case 2, and $-1.14 \mathrm{~cm}$ for Case 3. This indicates a backward movement during consolidation. An evaluation of the ground settlements and the lateral displacements at the toe of the embankment in the three cases indicates that in the case of a larger ground settlement, a smaller lateral displacement will develop due to consolidation.

\subsection{Overall deformation}

The deformed meshes of the model after 1000 days of consolidation in the three cases are presented in Figure 13, in which the deformations have been enlarged to 10 times the actual values. Since the deformations during and just after the construction were rather small, the final deformations after 1000 days are presented here for comparison. In all cases, the deformations are particularly localized in the upper part of the subsurface layer beneath the embankment. The deformation of the embankment is insignificant compared to that of the ground layer. For Case 1, a small deformation occurs below the embankment, as shown in Figure 13(a), while for Case 2, a large deformation is observed in Figure 13(b). The deformation becomes even larger when considering the strain dependency of the shear modulus and the structural degradation in Case 3, as the distorted mesh beneath the embankment can be seen in Figure 13(c). 


\subsection{Viscoplastic shear strain}

The accumulated viscoplastic shear strain is determined by the accumulation of the viscoplastic deviatoric stain rate, as defined by Equation (27). The results of the accumulated viscoplastic shear strain contours at each construction stage and during consolidation are presented in Figures 14, 15, and 16 for Cases 1, 2, and 3, respectively. As an elastic model is employed for the embankment layers, viscoplastic strain develops only in the subsurface layer. The maximum shear strain is distributed mostly in the upper part of the soft clay foundation close to the embankment. The shear strain distributions during construction are similar for Cases 1 and 2, but the differences become more evident during consolidation. In Case 2, with structural degradation parameters, extensive strain localization can be observed just beneath the embankment with larger amounts of viscoplastic shear strain than that in Case 1. Considering the strain dependency of the shear modulus in Case 3, however, larger strain is localized during construction and consolidation. The maximum value of accumulated viscoplastic shear strain in Cases 1 and 2, from $0.6 \%$ after the end of construction, as shown in Figures 14(d) and 15(d), increases to 9.57\% in Case 1 and $28.1 \%$ in Case 2 after 1000 days of consolidation, as shown in Figures 14(f) and 15(f). In Case 3, the maximum value of the accumulated viscoplastic shear strain at the end of the construction, after 40 days, is $0.84 \%$ which increases to $30.7 \%$ after 1000 days of consolidation.

\subsection{Excess pore water pressure}

The general features of the excess pore water pressure distribution are presented in Figure 17, which shows the excess pore water pressure contours during construction and consolidation for Case 1. The excess pore water pressure is generated in the ground layer in the whole depth below the filling zone with a maximum value of $36 \mathrm{kPa}$ immediately after the end of the construction and then dissipates during the consolidation and reaches about $30 \mathrm{kPa}$ after 1000 days (Figure 17(f)). As the permeability of the clay layer is rather low and the drainage boundary is located only at the top, the dissipation rate during the consolidation is not so high. The other cases exhibit approximately the same excess pore pressure distribution as Case 1. Figure 18 presents the contours of excess pore pressure for Case 3 at several construction steps. The variations in the pore pressure in Case 3 during the construction process, within 40 days, shown in Figures 18(a) $\sim$ (d) are the same as those in Case 1, shown in Figures 17(a) $\sim(d)$. Nevertheless, after the 
completion of loading, Case 3 demonstrates different responses, particularly in the strainlocalized region beneath the embankment. Figures 18(e) and 18(f) indicate the concentration of pore pressure contour lines just beneath the embankment in Case 3. This implies higher excess pore water pressure in that region compared to Case 1, shown in Figures 17(e) and (f), respectively.

In order to clarify the effect of destructuration on the pore pressure response in the strainlocalized region, the variations in excess pore water pressure versus time at four reference points beneath the embankment are presented in Figure 19 in a logarithmic scale for the three cases. These points are located at different levels where large strain occurs. All the cases produce rather similar amounts of excess pore water pressure during construction, but different amounts during consolidation. For Cases 2 and 3, temporary increases in pore water pressure are observed at 100 days, during consolidation, because of the consideration given to the structural parameters. As a larger structural parameter $\beta$ is employed in Case 3, a higher secondary generation is observed. Although the amounts of regenerated excess pore pressure at various points are less in Case 2 than those in Case 3, the effect of structural degradation is clearly observed. Comparing the variations in excess pore water pressure at different points in Case 3, shown in Figure 19(c), the secondary generated pore pressure at Points $\mathrm{C}$ and $\mathrm{D}$, located in the area with strain localization, are higher than those at Points $\mathrm{A}$ and $\mathrm{B}$.

It should be mentioned that the consideration of the strain-dependent shear modulus affects the pore water pressure response by changing structural parameter $\beta$ to a larger value. The anomalous build-up of pore water pressure after loading is observed; this is similar to the fieldmeasured evidence reported by Mesri and Choi (1979), Leroueil et al. (1979), Mitchell (1986), etc. This indicates the extensive microstructural changes in the clay layer in the localization area, which causes the unstable behavior during consolidation. In sensitive soft clays, the pore water pressure increases or becomes stagnant following the completion of the embankment construction, due to the collapse or the rearrangement of the initial clay structure. This is associated with the increase in viscoplastic strain.

\section{Conclusion}

The behavior of Osaka soft clay was modeled via an elasto-viscoplastic constitutive model. The effect of destructuration on the behavior of Osaka soft clay was studied. The destructuration was 
modeled by both viscoplastic structural degradation and a strain-dependent elastic shear modulus. The comparison of the predicted results with the laboratory test data under undrained triaxial compression conditions, significantly exhibited the efficiency of both destructuration aspects on the soft clay response. Structural degradation includes the unstable behavior during consolidation due to the microstructural changes in the soft clay skeleton which lead to the softening behavior after the peak point along the stress-strain relation curve, a rapid increase in the strain rate, and a temporary increase in pore water pressure during consolidation. The strain dependency of the elastic shear modulus is related to the non-linear behavior of the shear modulus, which is a function of the viscoplastic shear strain and the variation in mean effective stress. In order to predict the behavior of sensitive soft clay more accurately, it is necessary to take into account the strain dependency of the shear modulus in addition to the structural degradation parameters. The predicted results presented a good agreement with the corresponding experimental values. This agreement emphasizes the capability of the elasto-viscoplastic model to reproduce the behavior of sensitive soft clay.

The influence of the aspects of destructuration was then evaluated in a two-dimensional boundary value problem. The consolidation analysis of an embankment construction on a soft clay foundation was conducted by the finite element method through three cases. The results clarified the effects of these considerations of which large strain and consequent deformations developed due to the structural degradation during consolidation. Moreover, the secondary generation of pore pressure was observed after the completion of the construction in the narrow zone close to the embankment. Considering the strain dependency of the shear modulus, however, larger strain and larger displacements developed not only during the consolidation, but also during the construction of the embankment.

\section{Acknowledgments}

The authors are thankful for the partial support of the new technological development study group of the Kinki Regional Development Bureau. In addition, the support of the Yodogawa River Office in providing the experimental data is gratefully acknowledged. 


\section{Appendix: Finite element formulation}

\section{Equilibrium Equation}

Terzaghi's effective stress is adopted for the two-phase soil medium as

$$
T_{i j}=T_{i j}^{\prime}+U_{w} \delta_{i j}
$$

where $T_{i j}$ is the Cauchy stress tensor, $T_{i j}^{\prime}$ is the effective Cauchy stress tensor, $U_{w}$ is the pore water pressure, and $\delta_{i j}$ is Kronecker's delta.

Taking the time derivative of Equation (A1) yields

$$
\dot{T}_{i j}=\dot{T}_{i j}^{\prime}+\dot{U}_{w} \delta_{i j}
$$

For the finite element method, we used a rate type of equilibrium equation for the updated Lagrangian formulation. Assuming fully saturated conditions, the weak form of the equilibrium equation for the entire fluid-solid mixture in domain $V$ can be expressed as

$$
\int_{V} \hat{\dot{S}}_{j i, j} \delta v_{i} d V=0
$$

in which $\hat{\dot{S}}_{i j}$ is the total nominal stress rate tensor with respect to the current configuration and $\delta v_{i}$ is the virtual velocity vector component.

The relationship between the nominal stress rate tensor and the Cauchy stress rate tensor is given by

$$
\begin{gathered}
\hat{\dot{S}}_{i j}=\dot{T}_{i j}+L_{p p} T_{i j}-T_{i q} L_{j q} \\
\hat{\dot{S}}_{i j}^{\prime}=\dot{T}_{i j}^{\prime}+L_{p p} T_{i j}^{\prime}-T_{i q}^{\prime} L_{j q}
\end{gathered}
$$

where $\hat{\dot{S}}_{i j}^{\prime}$ is the effective nominal stress rate tensor and $L_{i j}$ is the velocity gradient tensor.

Combining Equations (A1) to (A5), the total nominal stress rate tensor can be related to the effective nominal stress rate tensor as

$$
\begin{gathered}
\hat{\dot{S}}_{i j}=\hat{\dot{S}}_{i j}^{\prime}+\dot{U}_{w} \delta_{i j}+B_{i j} \\
B_{i j}=L_{k k} U_{w} \delta_{i j}-U_{w} \delta_{i k} L_{j k}
\end{gathered}
$$

Using Green's theorem and Gauss's divergence theorem, Equation (A3) can be written as 


$$
\int_{\Gamma}\left(\hat{\dot{S}}_{j i} \delta v_{i}\right) n_{j} d \Gamma-\int_{V} \hat{\dot{S}}_{j i} \delta L_{i j} d V=0
$$

where $\Gamma$ denotes a boundary surface of the closed domain, $V$, and $n$ is the unit normal vector to boundary surface $\Gamma$. Incorporating Equation (A6) into Equation (A8) leads to

$$
\int_{V} \hat{\dot{S}}_{j i}^{\prime} \delta L_{i j} d V+\int_{V} \dot{U}_{w} \delta L_{i j} \delta_{i j} d V+\int_{V} B_{i j} \delta L_{i j} d V=\int_{\Gamma}\left(\hat{\dot{S}}_{j i} \delta v_{i}\right) n_{j} d \Gamma
$$

Using the Cauchy stress theorem, Equation (A9) is obtained as follows:

$$
\int_{V} \hat{\dot{S}}_{i j}^{\prime} \delta L_{i j} d V+\int_{V} \dot{U}_{w} \delta D_{k k} d V+\int_{V} B_{i j} \delta L_{i j} d V=\int_{\Gamma} \bar{S}_{t i} \delta v_{i} d \Gamma
$$

where $D_{i j}$ is the stretching tensor defined by $D_{i j}=\frac{1}{2}\left(L_{i j}+L_{j i}\right)$ and $\hat{S}_{t i}$ is the nominal traction vector given by $\bar{S}_{t i}=\hat{\dot{S}}_{j i} n_{j}$.

Substituting Equation (A5) into Equation (A10) results in

$$
\int_{V} \dot{T}_{i j}^{\prime} \delta D_{i j} d V+\int_{V} A_{i j} \delta L_{i j} d V+\int_{V} L_{k k} T_{i j}^{\prime} \delta L_{i j} d V+\int_{V} \dot{U}_{w} \delta D_{k k} d V+\int_{V} B_{i j} \delta L_{i j} d V=\int_{\Gamma} \bar{S}_{t i} \delta v_{i} d \Gamma
$$

in which

$$
A_{i j}=-\dot{T}_{j k}^{\prime} L_{i k}
$$

The objective Jaumann rate of Cauchy stress tensor $\hat{T}_{i j}^{\prime}$ is defined by means of Cauchy stress rate tensor $\dot{T}_{i j}^{\prime}$ and spin tensor $W_{i j}$ as

$$
\hat{T}_{i j}^{\prime}=\dot{T}_{i j}^{\prime}-W_{i k} T_{k j}^{\prime}+T_{i k}^{\prime} W_{k j}
$$

The constitutive equation is described using the Jaumann rate of Cauchy stress tensor $\hat{T}_{i j}^{\prime}$ and stretching tensor $D_{i j}$ as

$$
\hat{T}_{i j}^{\prime}=C_{i j k l}^{e}\left(D_{k l}-D_{k l}^{v p}\right)
$$

where $C_{i j k l}^{e}$ is the elastic tangential stiffness matrix and $D_{i j}^{v p}$ is the viscoplastic stretching tensor, which is related to the total stretching tensor as 


$$
D_{i j}=D_{i j}^{e}+D_{i j}^{v p}
$$

where $D_{i j}^{e}$ is the elastic stretching tensor defined as

$$
D_{i j}^{e}=\frac{1}{2 G} \dot{S}_{i j}+\frac{\kappa}{3\left(1+e_{0}\right)} \frac{\dot{T}_{m}^{\prime}}{T_{m}^{\prime}} \delta_{i j}
$$

in which $\dot{S}_{i j}$ is the deviatoric stress tensor rate $\left(\dot{S}_{i j}=\dot{T}_{i j}^{\prime}-\dot{T}_{m}^{\prime} \delta_{i j}\right)$. Viscoplastic stretching tensor $D_{i j}^{v p}$ is given by

$$
D_{i j}^{v p}=C_{i j k l}\left\langle\Phi\left(f_{y}\right)\right\rangle \frac{\partial f_{p}}{\partial T_{k l}^{\prime}}
$$

where \langle\rangle are Macaulay's brackets; $\left\langle\Phi\left(f_{y}\right)\right\rangle=\Phi\left(f_{y}\right)$, if $f_{y}>0$ and $\left\langle\Phi\left(f_{y}\right)\right\rangle=0$, if $f_{y} \leq 0$.

The tangent modulus method (Peirce, Shih and Needleman 1984) is implemented here to determine the viscoplastic stretching tensor. Hence, Equation (A14) can be rewritten in matrix form as

$$
\left\{\hat{T}^{\prime}\right\}=[C]\{D\}-\{Q\}
$$

where $[C]$ is the tangential stiffness matrix and $\{Q\}$ is the relaxation stress vector.

The substitution of Equation (A13) into Equation (A18) gives

$$
\left\{\dot{T}^{\prime}\right\}=[C]\{D\}-\{Q\}+\left\{W^{\prime}\right\}
$$

in which $\left\{W^{\prime}\right\}$ is the vector defined as $\left\{W^{\prime}\right\}=\{W T-T W\}$.

For the discretization of the weak form of the equilibrium equation, we adopt FEM with an isoperimetric element. The velocity and the pore water pressure are approximated as

$$
\begin{gathered}
\{v\}=[N]\left\{v^{*}\right\} \\
\left\{U_{w}\right\}=\left[N_{h}\right]\left\{U_{w}^{*}\right\}
\end{gathered}
$$

where $[N]$ and $\left[N_{h}\right]$ are the shape functions of the eight-node quadrilateral element for the nodal velocity vector and the four-node quadrilateral element for the pore water pressure, respectively. 
Combining Equation (A11) and Equation (A19) and using the FEM approximations, the final weak form of the equilibrium equation becomes

$$
[K]\left\{v^{*}\right\}-\int_{V}[B]^{T}\{Q\} d V+\int_{V}[B]^{T}\left\{W^{*}\right\} d V+\left[K_{L}\right]\left\{v^{*}\right\}+\left[K_{v}\right]\left\{\dot{U}_{w}^{*}\right\}=\{\dot{F}\}
$$

where

$$
\begin{gathered}
{[K]=\int_{V}[B]^{T}[C][B] d V} \\
{\left[K_{L}\right]=\int_{V}\left[B_{M}\right]^{T}\left[D_{s}\right]\left[B_{M}\right] d V+\int_{V}\left[B_{M}\right]^{T}[U]\left[B_{M}\right] d V+\int_{V}\left[B_{M}\right]^{T}\left\{T^{\prime}\right\}\left\{B_{v}\right\}^{T} d V} \\
{\left[K_{v}\right]=\int_{V}\left\{B_{v}\right\}\left\{N_{h}\right\}^{T} d V} \\
\{\dot{F}\}=\int_{\Gamma}[N]^{T}\left\{\bar{S}_{t}\right\} d \Gamma
\end{gathered}
$$

Using Euler's scheme, the nodal velocity vector and pore water pressure can be obtained as

$$
\begin{gathered}
\left\{v^{*}\right\}=\frac{\left\{\Delta u^{*}\right\}}{\Delta t} \\
\left\{\dot{U}_{w}^{*}\right\}=\frac{\left\{U_{w}^{*}\right\}_{t+\Delta t}-\left\{U_{w}^{*}\right\}_{t}}{\Delta t}
\end{gathered}
$$

where $\left\{\Delta u^{*}\right\}$ is the vector of the incremental nodal displacement. Incorporating Equations (A27) and (A28), Equation (A22) becomes

$$
\left[[K]+\left[K_{L}\right]\right]\left\{\Delta u^{*}\right\}_{t+\Delta t}+\left[K_{v}\right]\left\{U_{w}^{*}\right\}_{t+\Delta t}=\Delta t\{\dot{F}\}+\left[K_{v}\right]\left\{U_{w}^{*}\right\}_{t}+\Delta t\left\{\dot{F}^{*}\right\}-\Delta t\left\{\dot{F}^{w}\right\}
$$

where

$$
\begin{gathered}
\left\{\dot{F}^{*}\right\}=\int_{V}[B]^{T}\{Q\} d V \\
\left\{\dot{F}^{w}\right\}=\int_{V}[B]^{T}\left\{W^{\prime}\right\} d V
\end{gathered}
$$

\section{Continuity Equation}

Assuming the incompressibility of the soil particles and the pore water, the continuity equation is obtained from the mass conservation equation of the soil-water mixture as 


$$
\frac{k}{\gamma_{w}} U_{w, i i}+D_{i i}=0
$$

where $k$ is the coefficient of permeability, $D_{i i}$ is the stretching tensor, and $\gamma_{w}$ is the density of the pore water.

The weak form of the continuity equation is given by

$$
\int_{V}\left(\frac{k}{\gamma_{w}} U_{w, i i}+D_{i i}\right) \bar{W} d V=\frac{k}{\gamma_{w}} \int_{V} U_{w, i i} \bar{W} d V+\int_{V} D_{i i} \bar{W} d V=0
$$

in which $\bar{W}$ is a Galerkin weighted function for the continuity equation as $\bar{W}=\left\{N_{h}\right\}$. Proceeding with the similar procedure as described for the equilibrium equation, Equation (A33) becomes

$$
\frac{k}{\gamma_{w}} \int_{\Gamma} \bar{W} U_{w, i} n_{i} d \Gamma-\frac{k}{\gamma_{w}} \int_{V} \bar{W}_{, i} U_{w, i} d V+\int_{V} \bar{W} D_{i i} d V=0
$$

in which $n$ is the unit normal vector to boundary surface $\Gamma$.

Using FEM approximations for the pore water pressure, as described by Equation (A21), the discrete form of the continuity equation is given by

$$
\left[K_{v}\right]^{T}\left\{\Delta u^{*}\right\}-\Delta t\left(\left[K_{h}\right]+[V]\right)\left\{U_{w}^{*}\right\}_{t+\Delta t}=0
$$

where

$$
\begin{gathered}
{\left[K_{v}\right]^{T}=\int_{V}\left\{N_{h}\right\}\left\{B_{v}\right\}^{T} d V} \\
{\left[K_{h}\right]=\frac{k}{\gamma_{w}} \int_{V}\left[B_{h}\right]^{T}\left[B_{h}\right] d V} \\
\{V\}=-\frac{k}{\gamma_{w}} \int_{\Gamma}\left\{N_{h}\right\}\{n\}^{T}\left[B_{h}\right] d \Gamma
\end{gathered}
$$

\section{Discrete Equation}

Combining the equilibrium equation and the continuity equation, the final system of equations for the FEM analysis, based on the finite deformation theory, can be obtained as

$$
\left[\begin{array}{cc}
{[K]+\left[K_{L}\right]} & {\left[K_{v}\right]} \\
{\left[K_{v}\right]^{T}} & -\Delta t\left(\left[K_{h}\right]+[V]\right)
\end{array}\right]\left\{\begin{array}{l}
\left\{\Delta u_{t+\Delta t}^{*}\right\} \\
\left\{U_{w, t+\Delta t}^{*}\right\}
\end{array}\right\}=\left\{\begin{array}{c}
\Delta t\left\{\dot{F}^{t}\right\}+\left[K_{v}\right]\left\{U_{w, t}^{*}\right\} \\
0
\end{array}\right\}
$$

where 


$$
\left\{\dot{F}^{t}\right\}=\{\dot{F}\}+\left\{\dot{F}^{*}\right\}-\left\{\dot{F}^{w}\right\}
$$

\section{References}

Adachi, T., and Oka, F. 1982. Constitutive equations for normally consolidated clay based on elastoviscoplasticity. Soils and Foundations, 4, 57-70.

Adachi, T., Oka, F., Hirata, T., Hashimoto, T., Nagaya, J., Mimura, M., and Pradhan, T.B.S. 1995. Stressstrain and yielding characteristics of eastern Osaka clay. Soils and Foundations, 35(3), 1-13.

Burland, J.B. 1990. On the compressibility and shear strength of natural clays. Geotechnique, 40(3), 329378.

Hardin, B.O., and Drnevich, V.P. 1972. Shear modulus and damping in soils: design equation and curves. Journal of Soil Mechanics and Foundations, ASCE, 98, SM7, 667-692.

Ishihara, K. 1996. Soil behavior in earthquake geotechnics. UK: Oxford University Press, 85-152.

Karim, M.R., and Oka, F. 2010. An automatic time increment selection scheme for simulation of elastoviscoplastic consolidation of clayey soils. Geomechanics and Geoengineering: an International Journal, (to appear).

KG-NET, 2007. Ground of Kansai area especially Osaka plain to Osaka bay, Kansai Geo-informatics Research Committee: Shin Kansai Jiban, (article in Japanese).

Kimoto, S., and Oka, F. 2005. An elasto-viscoplastic model for clay considering destructuralization and consolidation analysis of unstable behavior. Soils and Foundations, 45(2), 29-42.

Kimoto, S., Oka, F., and Higo, Y. 2004. Strain localization analysis of elasto-viscoplastic soil considering structural degradation. Computer Methods in Applied Mechanics and Engineering, 193, 2845-2866.

Kimoto, S., Oka, F., Watanabe, T., and Sawada, M. 2007. Improvement of the viscoplastic potential and static yield function for the elasto-viscoplastic constitutive model. Proc. of $62^{\text {nd }}$ Annual Meeting of JSCE, Hiroshima, 637-638, (article in Japanese).

Kinki Regional Development Bureau. 2009. Geotechnical investigation report of Torishima super-levee project. Osaka, Japan.

Kokusho, T., Yoshida, Y., and Esashi, Y. 1982. Dynamic properties of soft clays for wide strain range. Soils and Foundations, 22, 1-18.

Kovacs, W.D., Seed, H.B., and Chan, C.K. 1971. Dynamic modulus and damping ratio for a soft clay. Journal of Soil Mechanics and Foundations, ASCE, 97, SM1, 59-75.

Lavallee, J.G., St-Arnaud, G., Gervais, R., and Hammamji, Y. 1992. Stability of the Olga C test embankment. ASCE Geotechnical Special Publication No. 31, Stability and Performance of Slopes and Embankments II, Berkeley, California, Seed and Boulanger eds. ASCE, 2, 1006-1021. 
Leroueil, S., Tavenas, F., Brucy, F., La Rochelle, P., and Roy, M. 1979. Behavior of destructed natural clays. Journal of Geotechnical Engineering, 115(6), 759-778.

Mesri, G., and Choi, Y.K. 1979. Excess pore water pressure during consolidation. Proc. 6th Asian Regional Conf. on SMFE, 1, 151-154.

Mitchell, J.K. 1986. Practical problems from surprising soil behavior. $20^{\text {th }}$ Terzaghi Lecture, Journal of Geotechnical Engineering, ASCE, 112(3), 259-289.

Nova, R. 1982. A viscoplastic constitutive model for normally consolidated clay. Proc. of IUTAM Conf. on Deformation and Failure of Granular Materials, Vermeer and Luger eds. Blakema, 287-295.

Ogisako, E., Nishio, S., Denda, A., Oka, F., and Kimoto, S. 2007. Simulation of triaxial compression tests on soil samples obtained from seabed ground in deep sea by elasto-viscoplastic constitutive equation. Proc. of the Seventh ISOPE Ocean Mining \& Gas Hydrates Symposium, Lisbon, Portugal, Chung and Komai eds. ISOPE, 63-68.

Oka, F., Feng, H., Kimoto, S., Kodaka, T., and Suzuki, H. 2008. A numerical simulation of triaxial test of unsaturated soil at constant water and air content by using an elasto-viscoplastic model. Unsaturated soils: Advances in Geo-Engineering, Toll, Augrade, Gallipoli, and Wheeler eds. Taylor and Francis Group, 735-741.

Oka, F., Higo, Y., and Kimoto, S. 2002. Effect of dilatancy on the strain localization of water-saturated elasto-viscoplastic soil. International Journal of Solids and Structures, 39, 3625-3647.

Oka, F., Kodaka, T., Kimoto, S., Ichinose, T., and Higo, Y. 2005. Strain localization of rectangular clay specimens under undrained triaxial compression conditions. Proc. $16^{\text {th }} I C S M G E$, Osaka, 2, 841-844.

Oka, F., Tavenas, F., and Leroueil, S. 1991. An elasto-viscoplastic FEM analysis of sensitive clay foundation beneath embankment. Proc. $7^{\text {th }}$ Int. Conf. on Computer Method and Advanced in Geomechanics. Cairns, Beer, Booker, and Carter eds. Balkema, 2, 1023-1028.

Peirce, D., Shih, C.F., and Needleman, A. 1984. A tangent modulus method for rate dependent solids. Computer and Structures, 18(5), 845-887.

Perzyna, P. 1963. The constitutive equations for work-hardening and rate sensitive plastic materials. In Proc. of Vibrational Problems, Warsaw, 4(3), 281-290.

Potts, D.M., and Zdravkovic, L. 1999. Finite element analysis in geotechnical engineering: theory. UK: Thomas Telford.

Roscoe, K.H., Schofield, A.N., and Thurairajah, A. 1963. Yielding of clays in states wetter than critical. Geotechnique, 13(3), 211-240.

Seed, H.B., Wong, R.T., Idriss, I.M., and Tokimatsu, K. 1986. Moduli and damping factors for dynamics analyses of cohesionless soils. Journal of Geotechnical Engineering, 112(11), 1016-1032.

Sekiguchi, H. 1977. Rheological characteristics of clays, Proc. 9th ICSMFE, 1, Tokyo, 289-292. 
Terzaghi, K., 1944. Ends and means in soil mechanics. Engineering Journal, Canada, 27, 608-613.

Wang, G.X., and Kuwano, J. 1999. Modeling of strain dependency of shear modulus and damping of clayey sand. Soil Dynamics and Earthquake Engineering, 18, 463-471.

Yin, J.-H., Graham, J. 1999. Elasto visco-plastic modelling of the time-dependent stress-strain behavior of soils. Canadian Geotechnical Journal, 36(4), 736-745.

Zienkiewicz, O.C., Humpheson, C., and Lewis, R.W. 1975. Associated and non-associated viscoplasticity and plasticity in soil mechanics. Geotechnique, 25(4), 671-689. 


\section{List of tables}

Table 1. Material parameters of soft clay layer Ac2.

Table 2. Strain-dependent parameter and modified values for the structural parameter.

Table 3. Specifications for each case in the 2D numerical analysis.

Table 4. Material parameters for the embankment and the ground layers.

\section{List of figures}

Figure 1. Overconsolidation boundary surface, static yield function and viscoplastic potential function.

Figure 2. Soil profile in Torishima, Osaka.

Figure 3. Stress-strain relations during triaxial tests and simulated results considering only the structural degradation.

Figure 4. Stress paths during triaxial tests and simulated results considering only the structural degradation, $M=\left(q / \sigma_{m}^{\prime}\right)_{\text {failure }}$.

Figure 5. Stress-strain relations during triaxial tests and simulated results considering the structural degradation and strain-dependent shear modulus.

Figure 6. Stress paths during triaxial tests and simulated results considering the structural degradation and strain-dependent shear modulus, $M=\left(q / \sigma_{m}^{\prime}\right)_{\text {failure }}$.

Figure 7. Finite element mesh and boundary conditions for the embankment construction.

Figure 8. Loading profile based on the construction stages.

Figure 9. Ground settlement profiles during and after construction for the different cases.

Figure 10. Ground settlements versus time at the embankment centerline.

Figure 11. Time-settlement at the toe of the embankment (9.5 $\mathrm{m}$ from the centerline).

Figure 12. Lateral displacements under the toe of the embankment during and after construction.

Figure 13. Deformed meshes after 1000 days of consolidation for the different cases: (a) Case 1,

(b) Case 2, and (c) Case 3 (deformations have been enlarged 10 times).

Figure 14. Viscoplastic shear strain contours for Case 1 on various days: (a) 10 days, (b) 20 days,

(c) 30 days, (d) 40 days, (e) 100 days, and (f) 1000 days.

Figure 15. Viscoplastic shear strain contours for Case 2 on various days: (a) 10 days, (b) 20 days, (c) 30 days, (d) 40 days, (e) 100 days, and (f) 1000 days.

Figure 16. Viscoplastic shear strain contours for Case 3 on various days: (a) 10 days, (b) 20 days, (c) 30 days, (d) 40 days, (e) 100 days, and (f) 1000 days.

Figure 17. Excess pore water pressure contours for Case 1 on various days: (a) 10 days, (b) 20 days, (c) 30 days, (d) 40 days, (e) 100 days, and (f) 1000 days.

Figure 18. Excess pore water pressure contours for Case 3 on various days: (a) 10 days, (b) 20 days, (c) 30 days, (d) 40 days, (e) 100 days, and (f) 1000 days.

Figure 19. Excess pore water pressure versus time for the different cases. 
Table 1. Material parameters of soft clay layer Ac2.

\begin{tabular}{lrrrr}
\hline & Ac2-U & Ac2-M & Ac2-L \\
\hline Depth $(\mathrm{m})$ & & $11.0-15.0$ & $15.0-19.0$ & $19.0-23.0$ \\
& & Tw 2-1-2 & Tw 2-2-1 & Tw 2-3-1 \\
Test no. & Tw 2-1-2b & Tw 2-2-2 & Tw 2-3-2 \\
\hline Initial void ratio & $e_{0}$ & 1.25 & 1.65 & 1.42 \\
Poisson's ratio & $v$ & 0.3 & 0.3 & 0.3 \\
Initial elastic shear modulus ${ }^{(1)}$ & $G_{0}(k P a)$ & 3759 & 3927 & 5993 \\
Compression index & $\lambda$ & 0.341 & 0.593 & 0.652 \\
Swelling index & $\kappa$ & 0.019 & 0.027 & 0.014 \\
Stress ratio at failure & $M^{*}{ }_{m c}$ & 1.24 & 1.18 & 1.12 \\
Viscoplastic parameter & $m^{\prime}$ & 24.68 & 28.2 & 21.15 \\
Viscoplastic parameter & $C_{1}(1 / s)$ & $3.83 \times 10^{-11}$ & $1.85 \times 10^{-11}$ & $8.99 \times 10^{-11}$ \\
Viscoplastic parameter & $C_{2}(1 / s)$ & $3.83 \times 10^{-11}$ & $1.85 \times 10^{-11}$ & $8.99 \times 10^{-11}$ \\
Structural parameter & $n=\sigma_{\text {maf }}^{\prime} / \sigma_{m a i}^{\prime}$ & 0.83 & 0.67 & 0.60 \\
Structural parameter & $\beta$ & 5 & 10 & 15 \\
\hline
\end{tabular}

(1) Based on the mean effective stress at the depth of the specimen 
Table 2. Strain-dependent parameter and modified values for the structural parameter.

\begin{tabular}{lrrrr}
\hline & Ac2-U & Ac2-M & Ac2-L \\
\hline Test no. & & Tw 2-1-2 & Tw 2-2-1 & Tw 2-3-1 \\
& Tw 2-1-2b & Tw 2-2-2 & Tw 2-3-2 \\
\hline Strain-dependent parameter & $\alpha$ & 20 & 10 & 10 \\
Structural parameter & $\beta$ & 10 & 15 & 20 \\
\hline
\end{tabular}


Table 3. Specifications for each case in the 2D numerical analysis.

\begin{tabular}{lcc}
\hline & $\begin{array}{c}\text { Structural } \\
\text { degradation }\end{array}$ & $\begin{array}{c}\text { Strain } \\
\text { dependency of } \\
\text { shear modulus }\end{array}$ \\
\hline Case 1 (No structural degradation: $\beta=0, \alpha=0)$ & $\times$ & $\times$ \\
Case 2 (Structural degradation: $\beta=10, \alpha=0)$ & $\checkmark$ & $\times$ \\
Case 3 (Structural degradation + Strain dependency of $G: \beta=15, \alpha=10)$ & $\checkmark$ & $\checkmark$ \\
\hline$\checkmark:$ Considered, $\times$ : Not considered. & &
\end{tabular}


Table 4. Material parameters for the embankment and the ground layers.

\begin{tabular}{lccccccccccccccc}
\hline & $k$ & $\gamma_{t}$ \\
Parameters & $(\mathrm{m} / \mathrm{s})$ & $\left(\mathrm{kN} / \mathrm{m}^{3}\right)$ & $e_{0}$ & $\begin{array}{c}G_{0} \\
(\mathrm{kPa})\end{array}$ & OCR & $\lambda$ & $\kappa$ & $M_{m c}^{*}$ & $m$ & $\begin{array}{c}C_{1}, C_{2} \\
(1 / s)\end{array}$ & $n$ & $\beta$ & $\alpha$ \\
\hline Embankment & $1.00 \times 10^{-5}$ & 19.8 & 0.8 & 4300 & & & & & & & & & \\
Ground (Ac2-M) & $3.85 \times 10^{-10}$ & 16.0 & 1.65 & 3930 & 1.10 & 0.593 & 0.027 & 1.18 & 28.2 & $1.85 \times 10^{-11}$ & 0.67 & $10,15^{(\mathbf{1})}$ & 0,10 \\
\hline (1) Modified value after strain-dependent shear modulus consideration
\end{tabular}

(1) Modified value after strain-dependent shear modulus consideration 


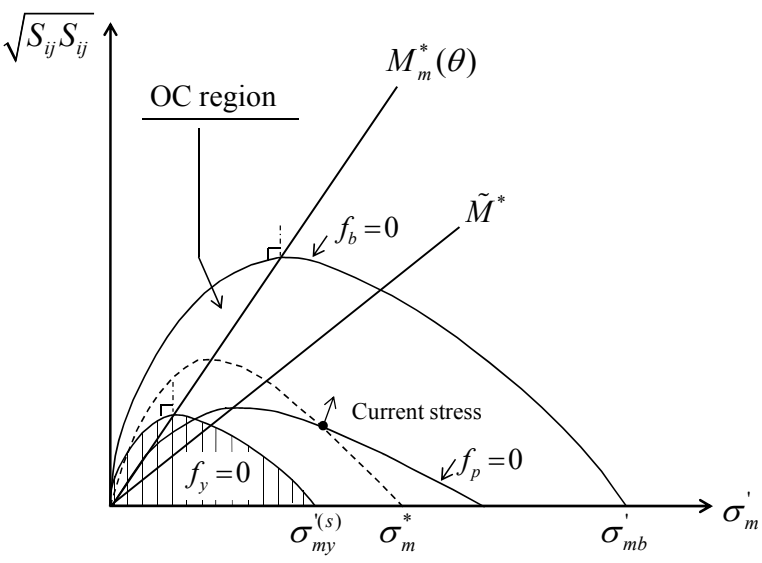

(a) OC region

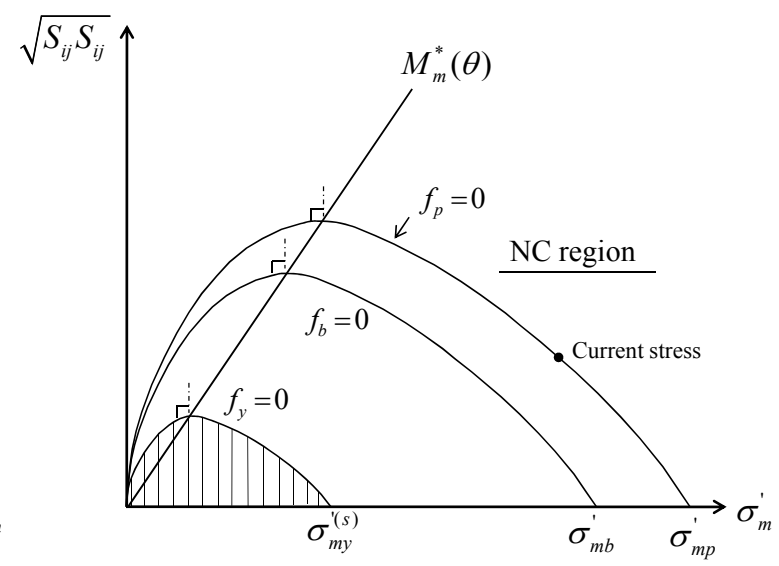

(b) NC region

Figure 1. Overconsolidation boundary surface, static yield function and viscoplastic potential function. 


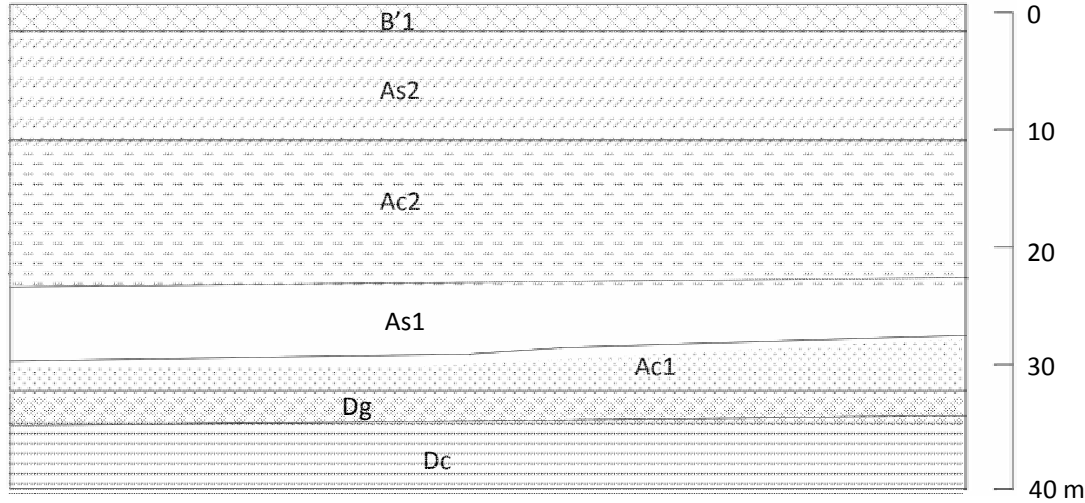

Figure 2. Soil profile in Torishima, Osaka. 

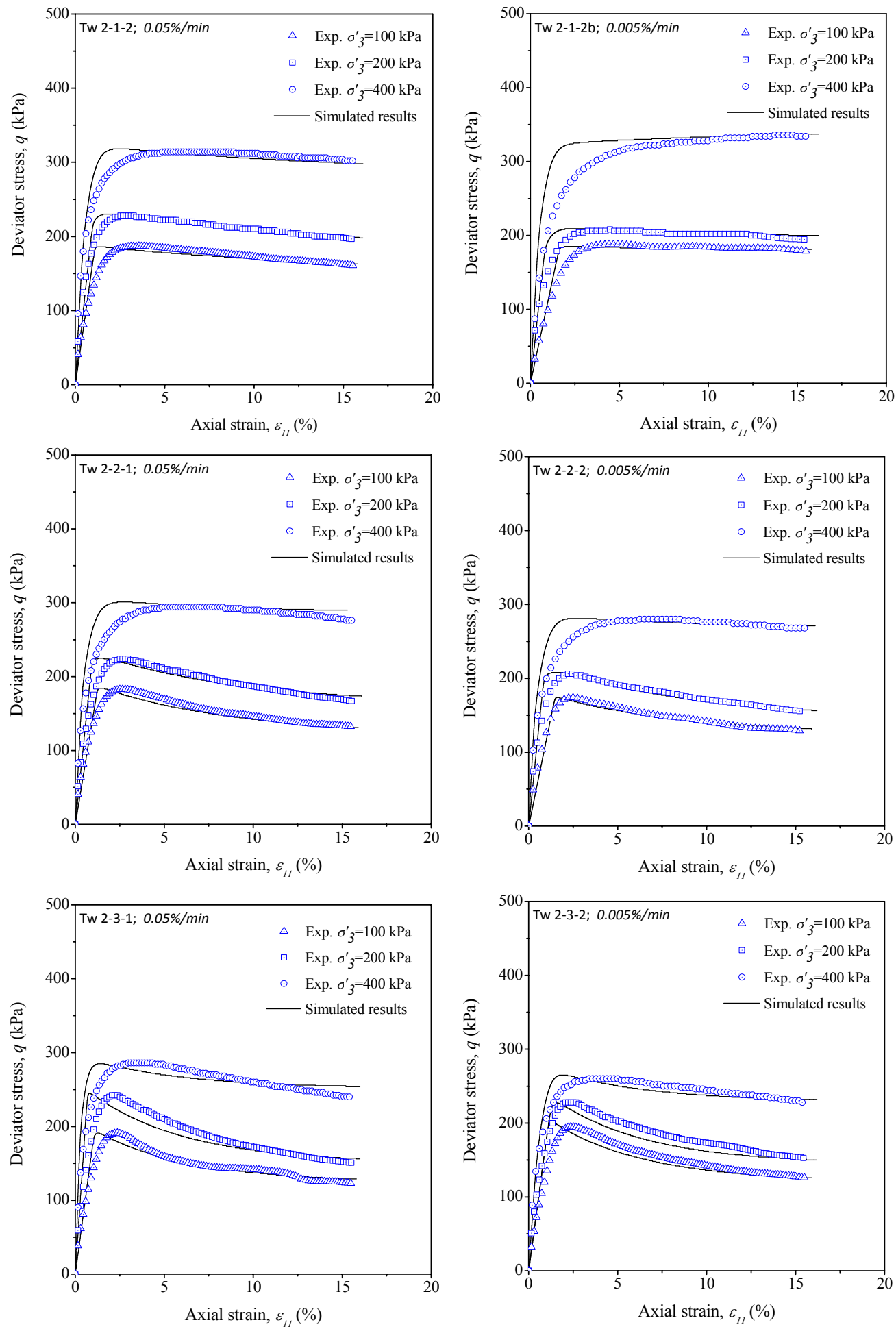

Figure 3. Stress-strain relations during triaxial tests and simulated results considering only the structural degradation. 

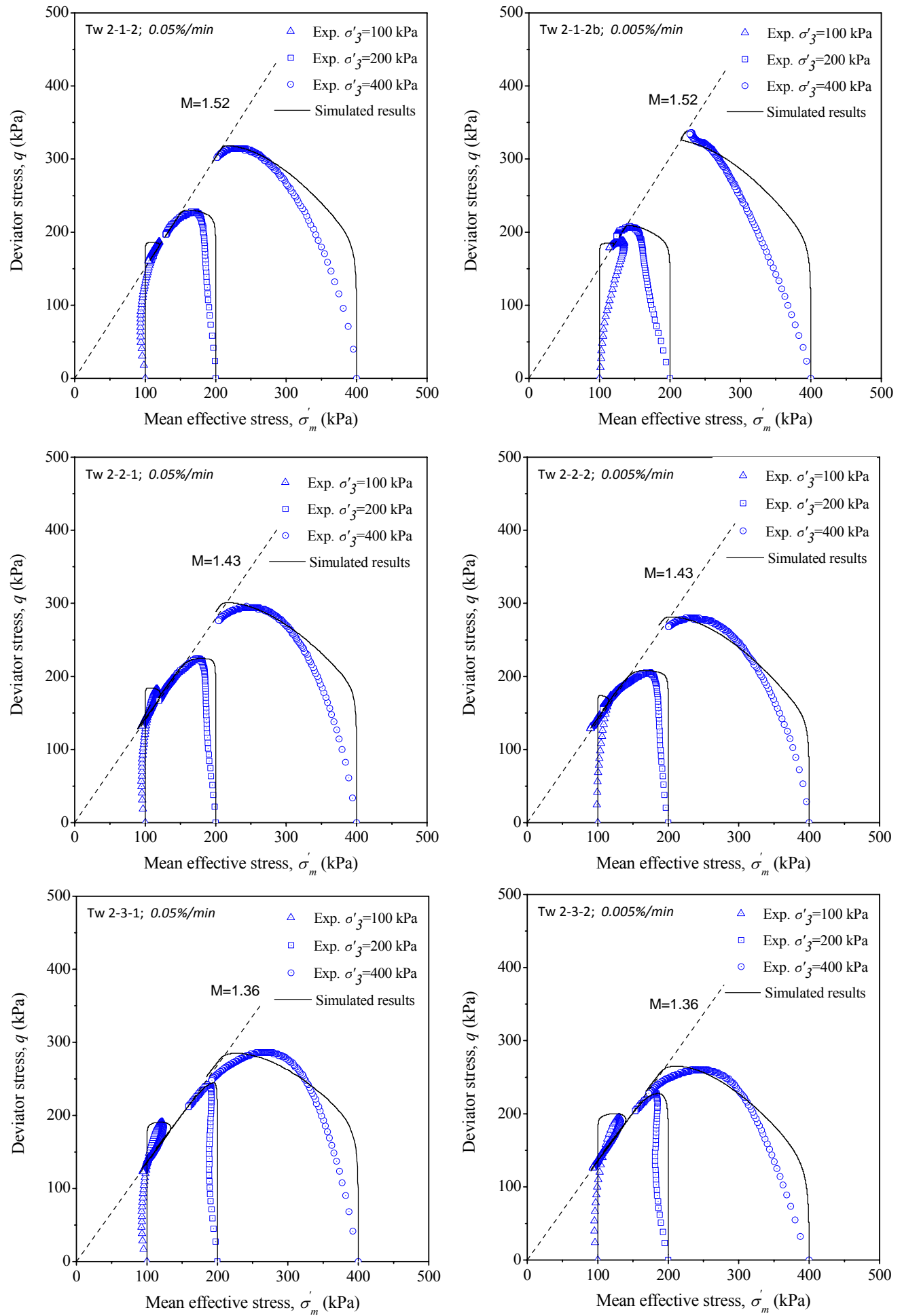

Figure 4. Stress paths during triaxial tests and simulated results considering only the structural degradation, $M=\left(q / \sigma_{m}^{\prime}\right)_{\text {failure }}$. 

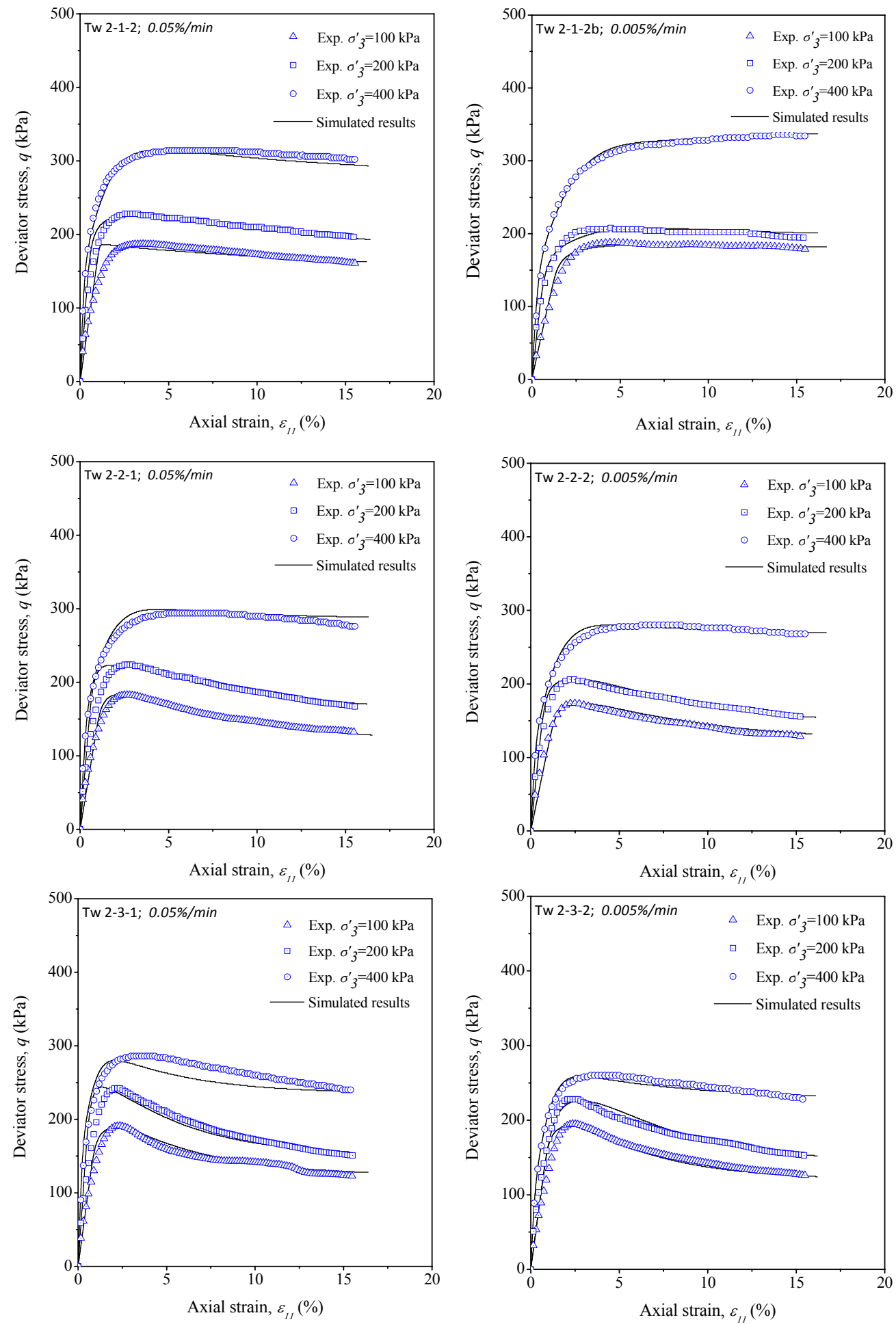

Figure 5. Stress-strain relations during triaxial tests and simulated results considering the structural degradation and strain-dependent shear modulus. 

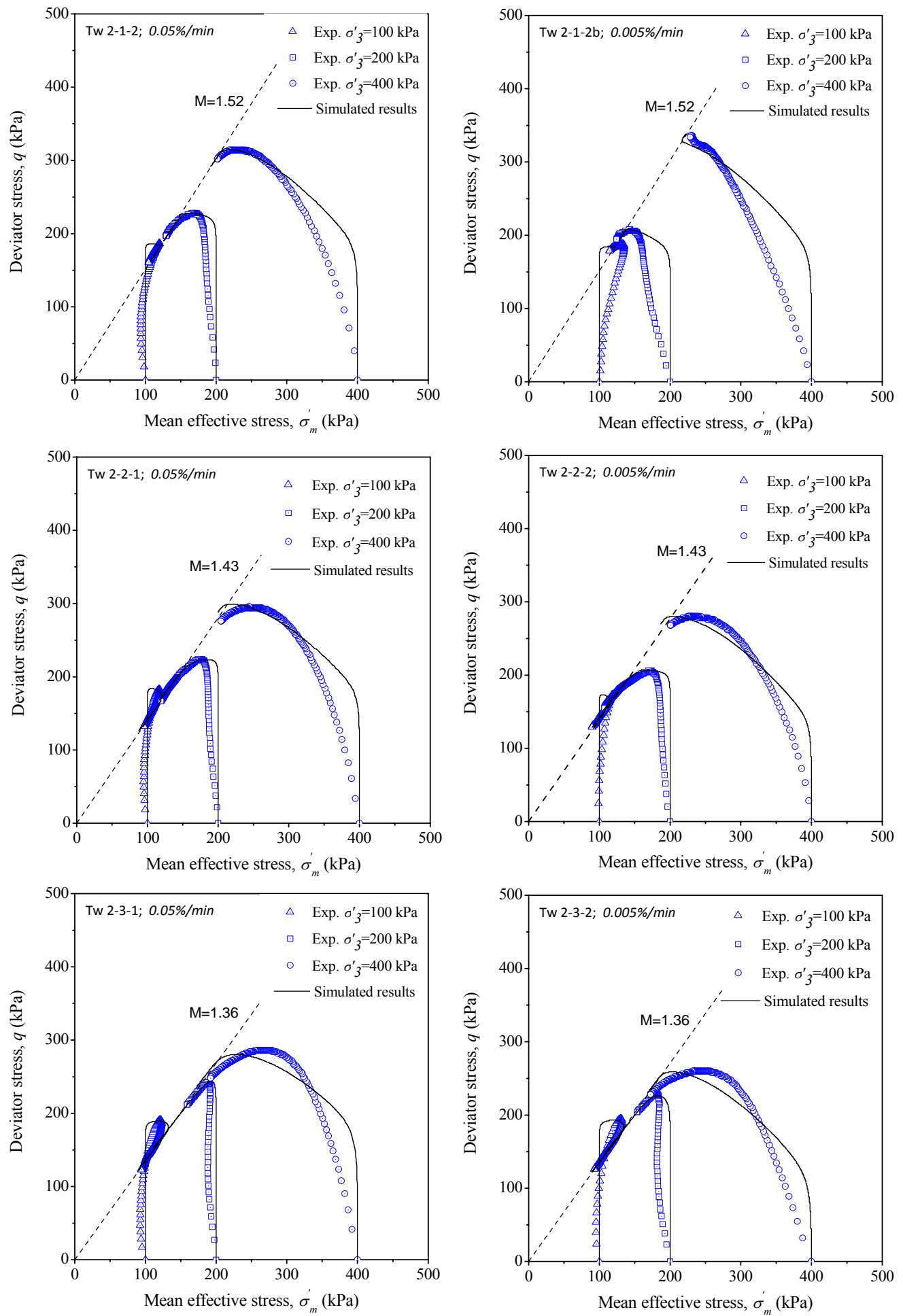

Figure 6. Stress paths during triaxial tests and simulated results considering the structural degradation and strain-dependent shear modulus, $M=\left(q / \sigma_{m}^{\prime}\right)_{\text {failure }}$. 


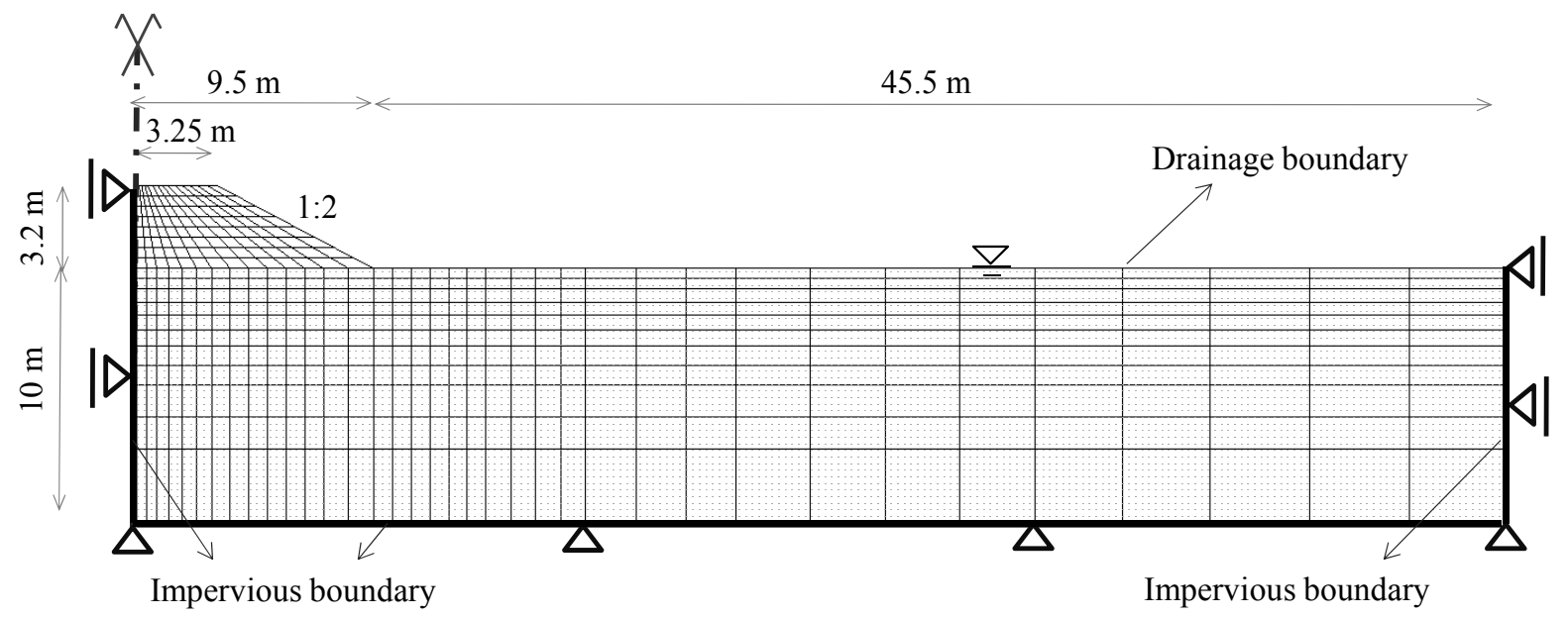

Figure 7. Finite element mesh and boundary conditions for the embankment construction. 


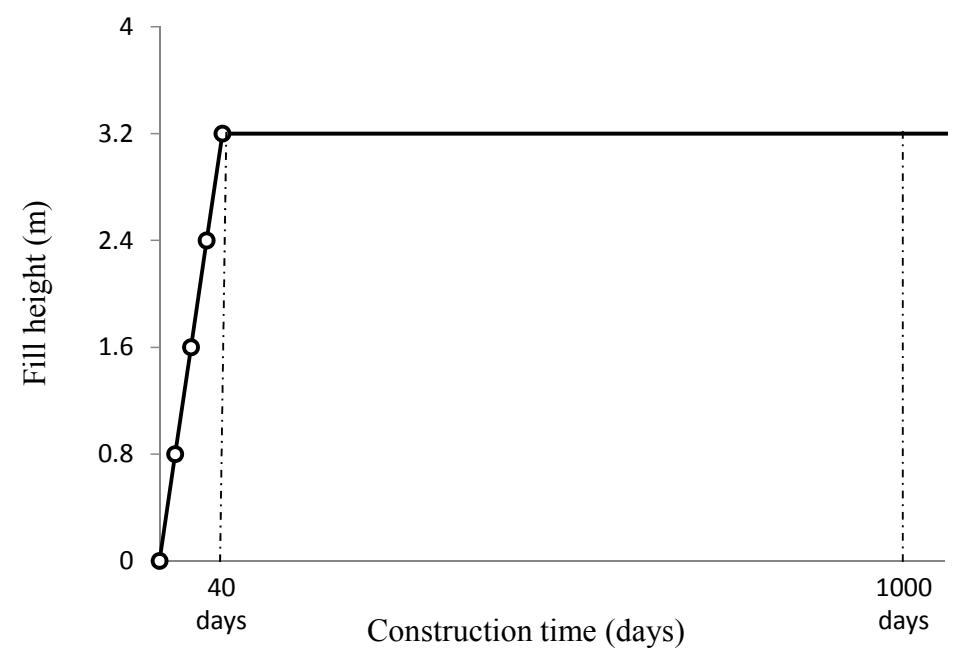

Figure 8. Loading profile based on the construction stages. 
(a)

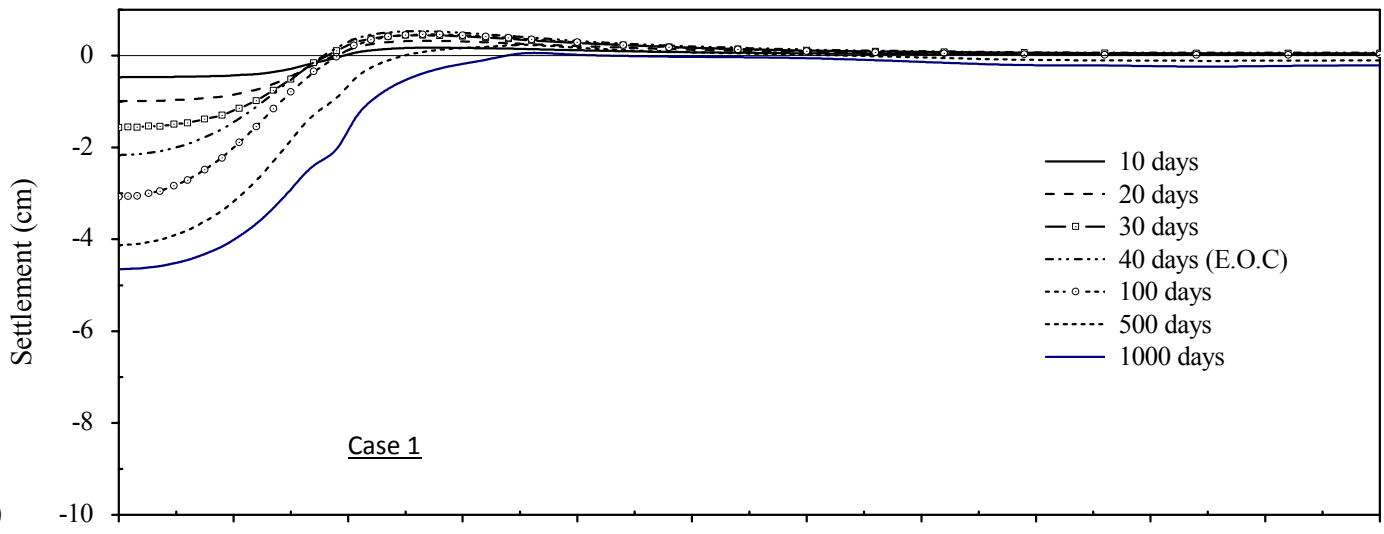

(b)
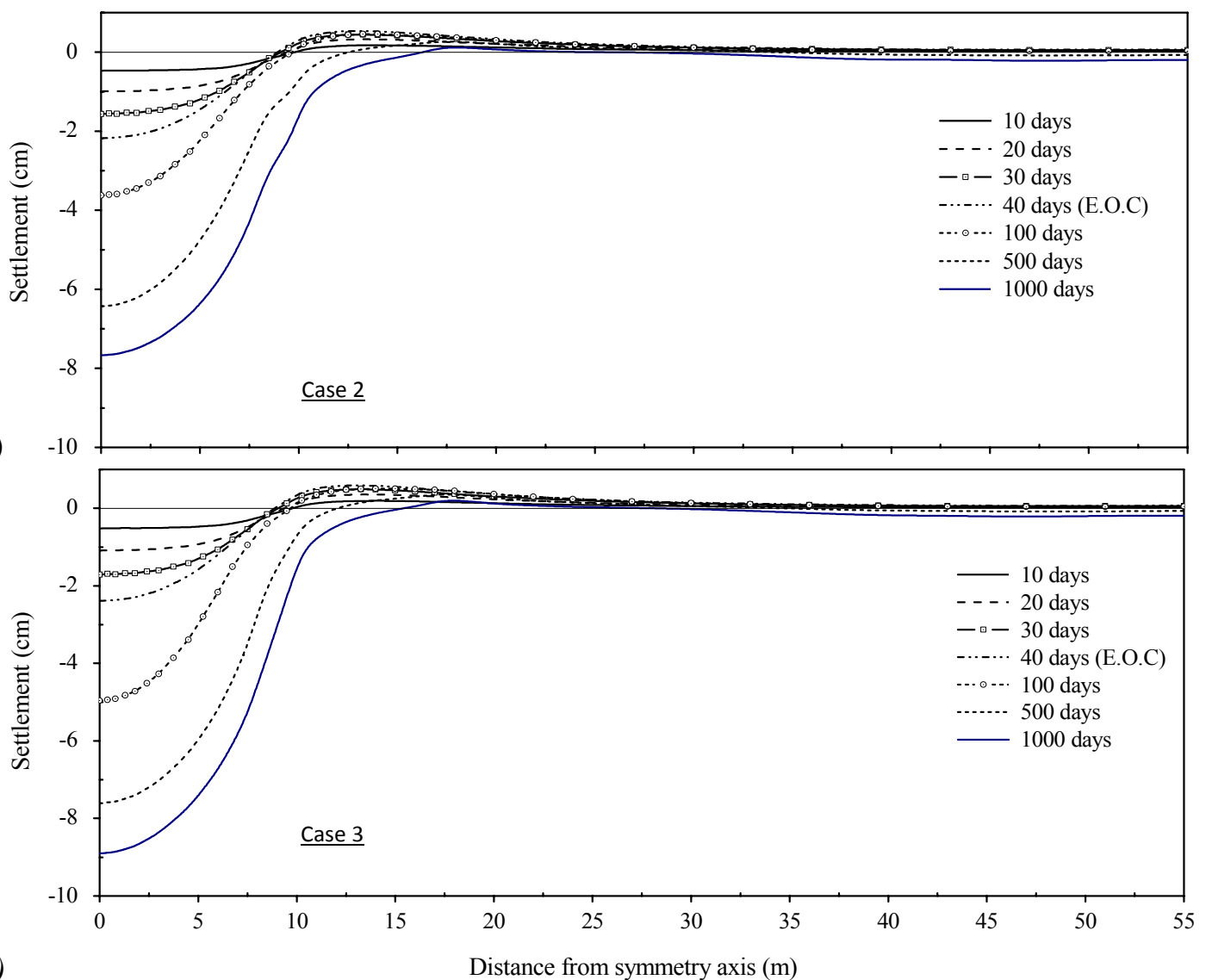

Figure 9. Ground settlement profiles during and after construction for the different cases. 


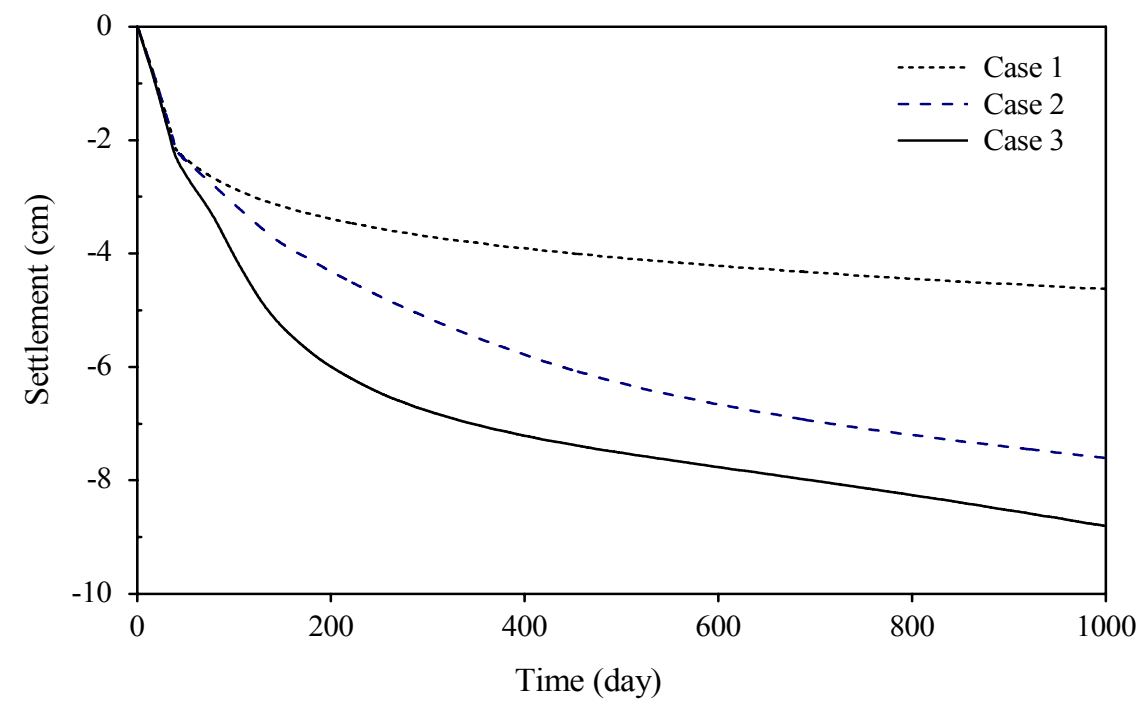

Figure 10. Ground settlements versus time at the embankment centerline. 


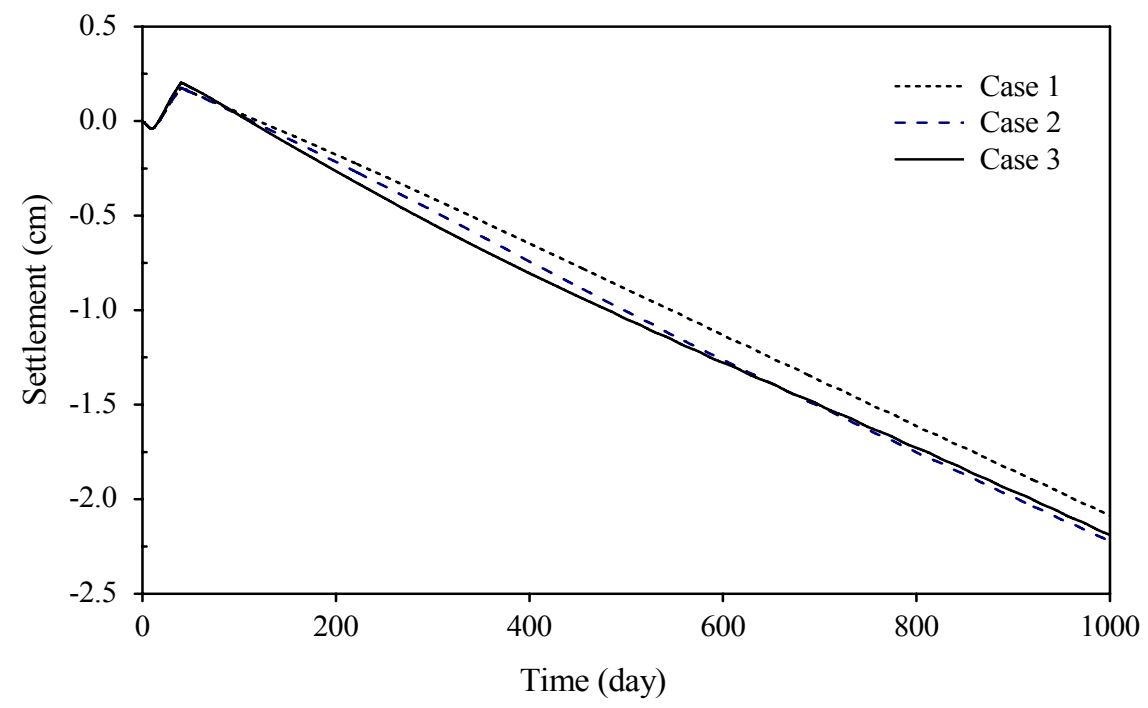

Figure 11. Time-settlement at the toe of the embankment (9.5 $\mathrm{m}$ from the centerline). 
(a)
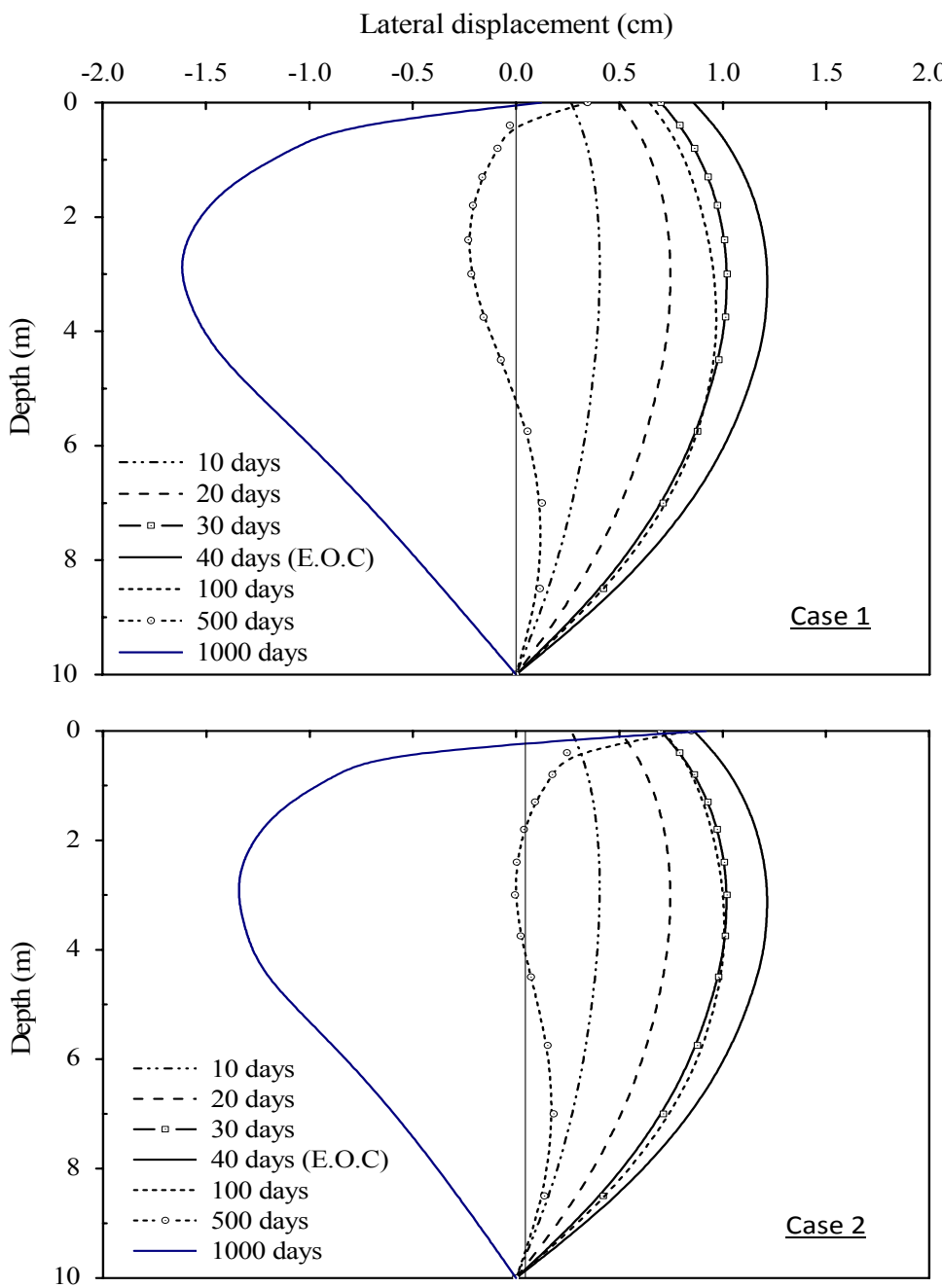

(b)

(c)

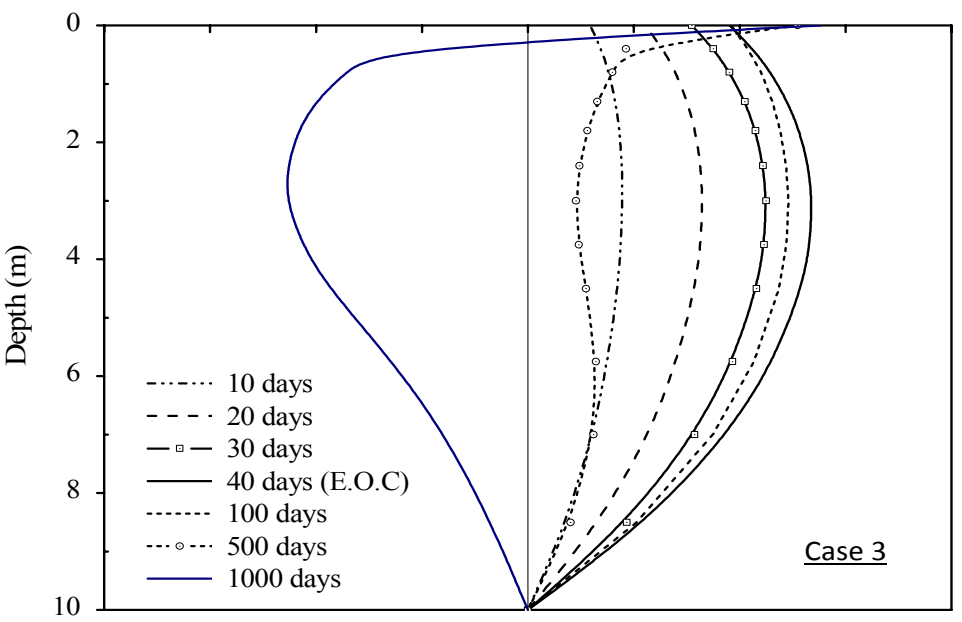

Figure 12. Lateral displacements under the toe of the embankment during and after construction. 
(a)
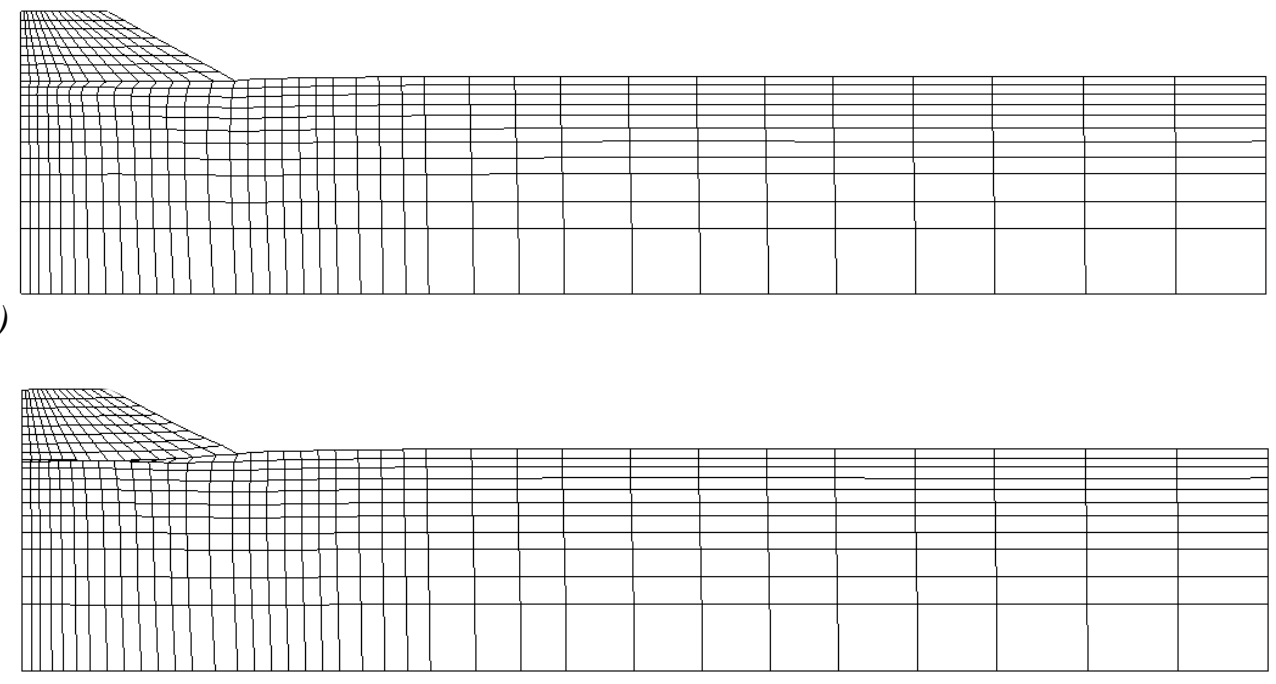

(b)

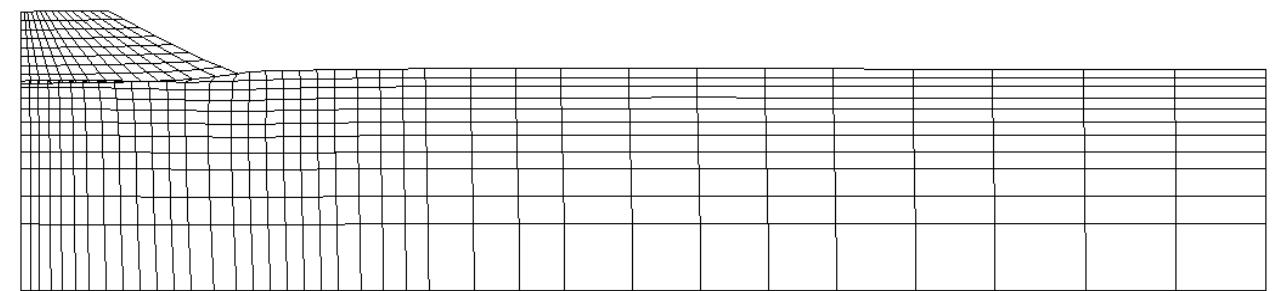

(c)

Figure 13. Deformed meshes after 1000 days of consolidation for the different cases: (a) Case 1, (b) Case 2 , and (c) Case 3 (deformations have been enlarged 10 times). 
(a)

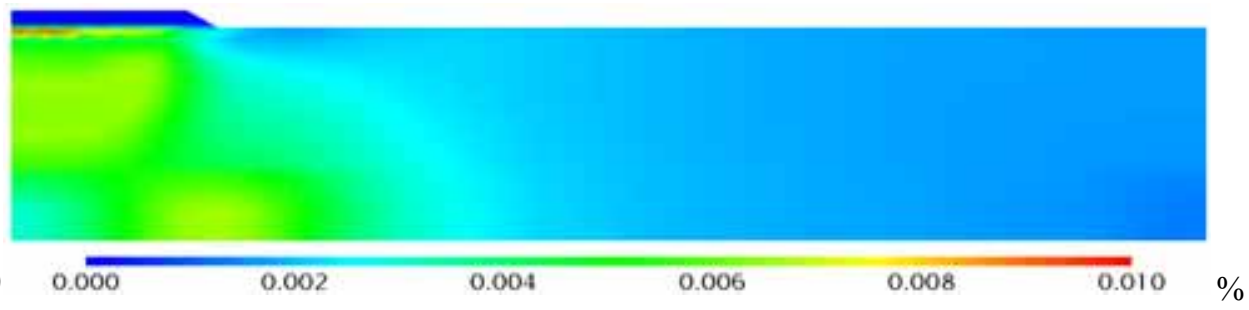

(b)

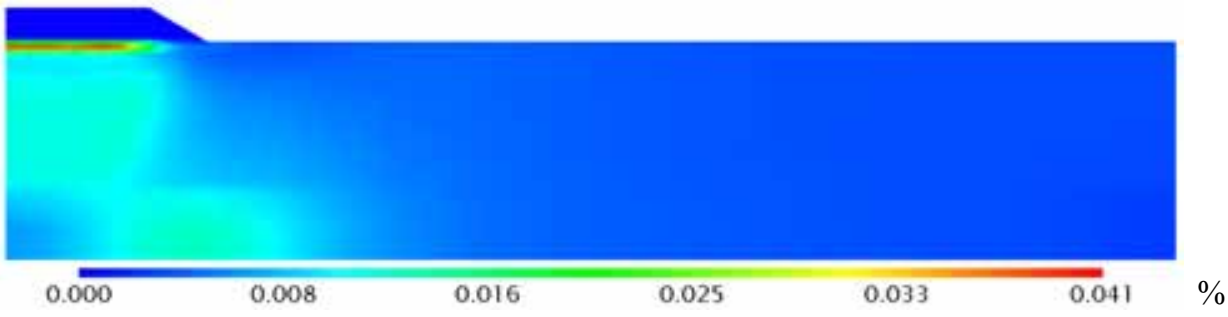

(c)
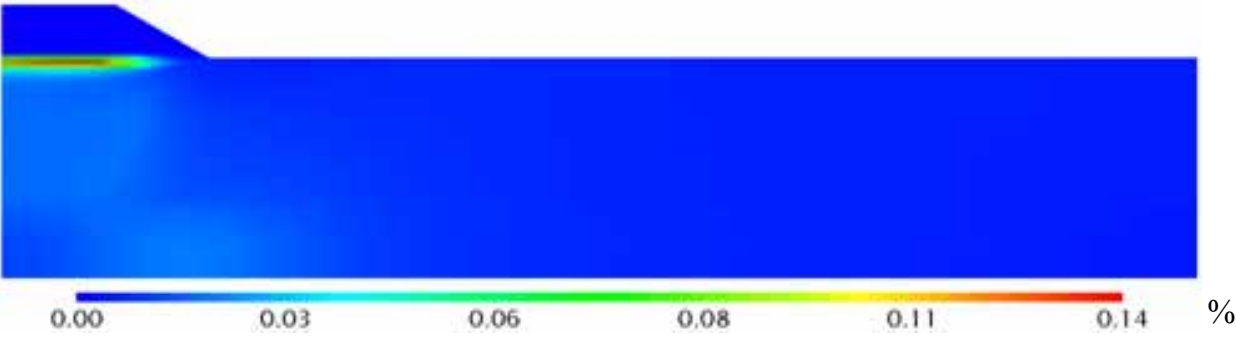

(d)
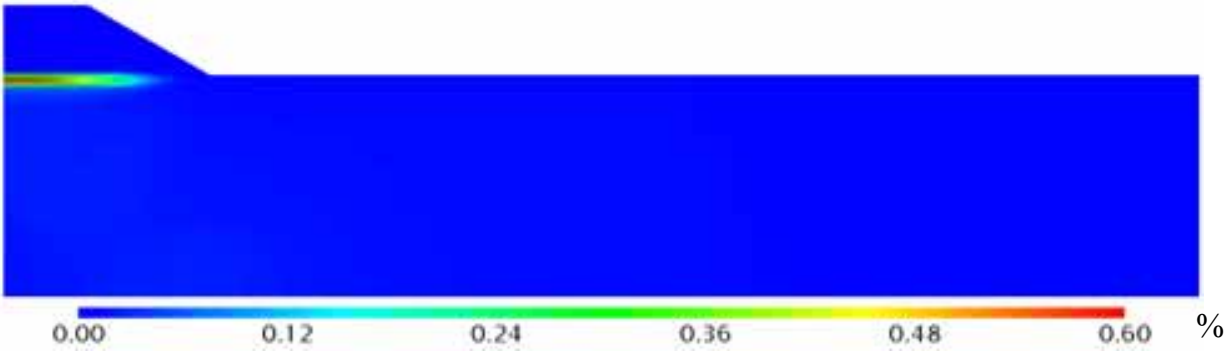

(e)

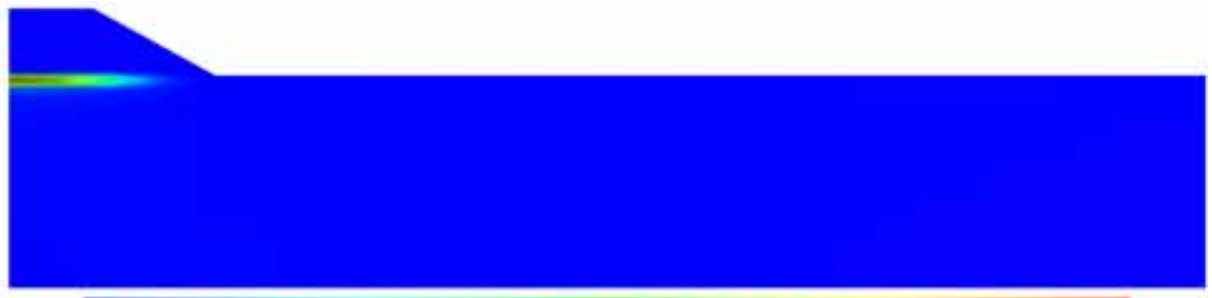

)
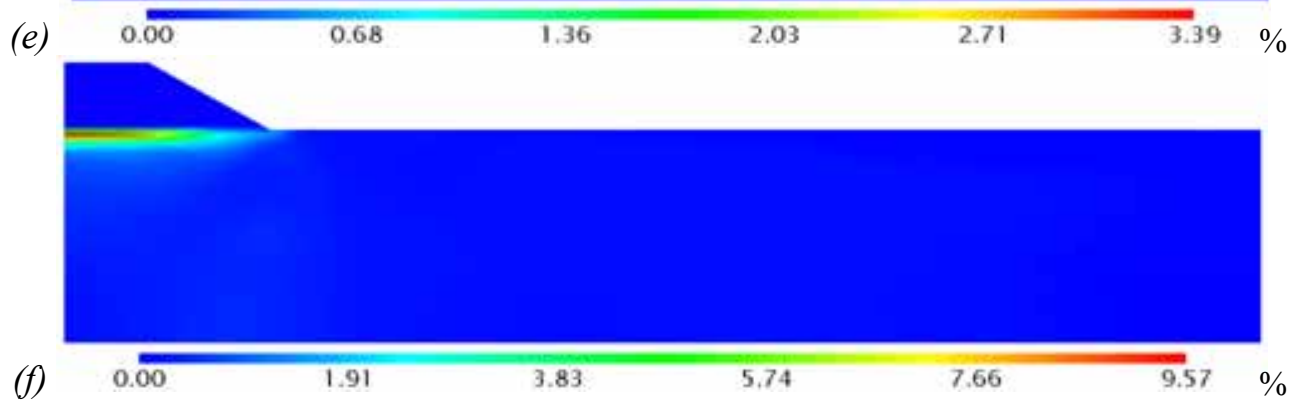

Figure 14. Viscoplastic shear strain contours for Case 1 on various days: (a) 10 days, (b) 20 days, (c) 30 days, (d) 40 days, (e) 100 days, and (f) 1000 days. 


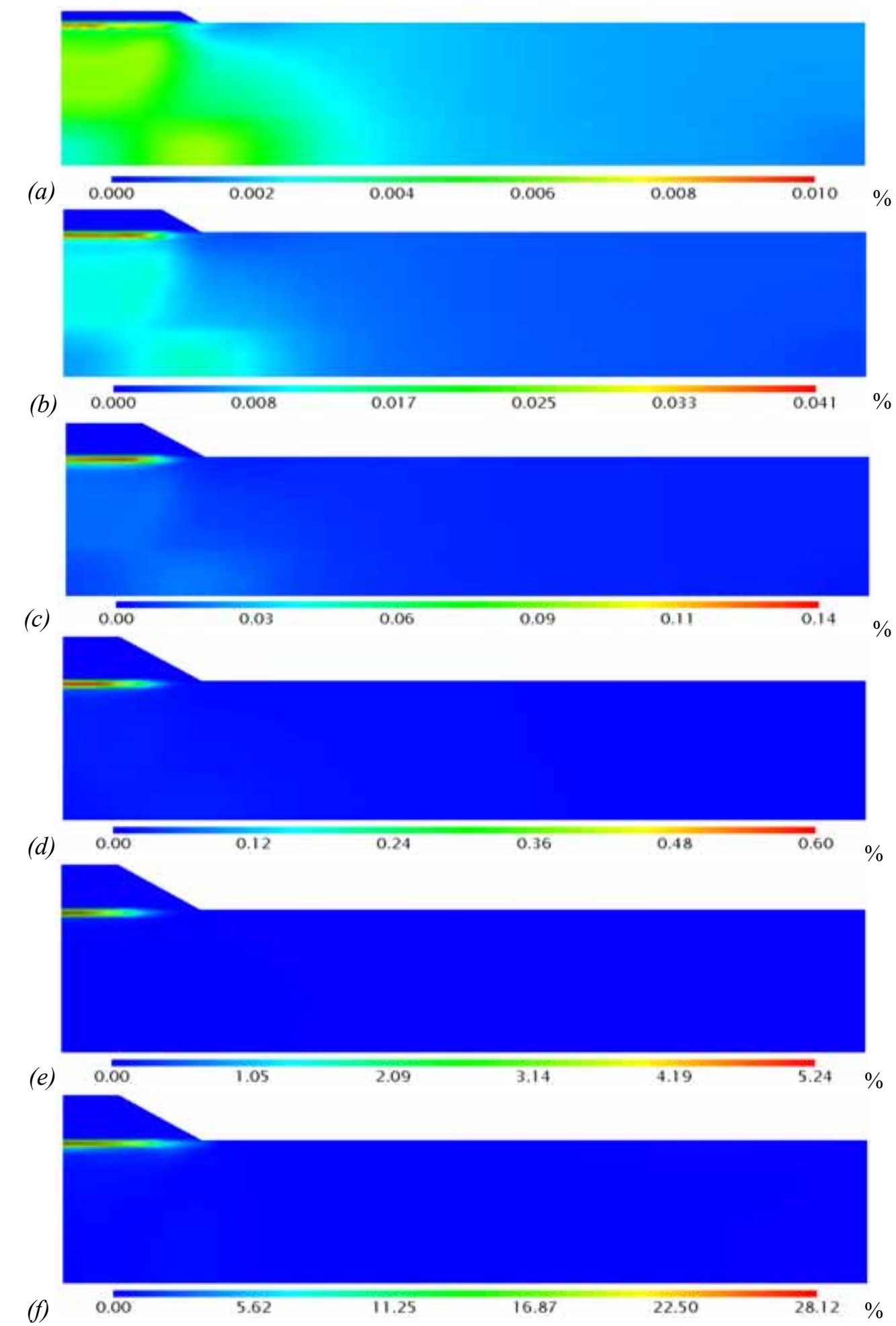

Figure 15. Viscoplastic shear strain contours for Case 2 on various days: (a) 10 days, (b) 20 days, (c) 30 days, (d) 40 days, (e) 100 days, and (f) 1000 days. 
(a)
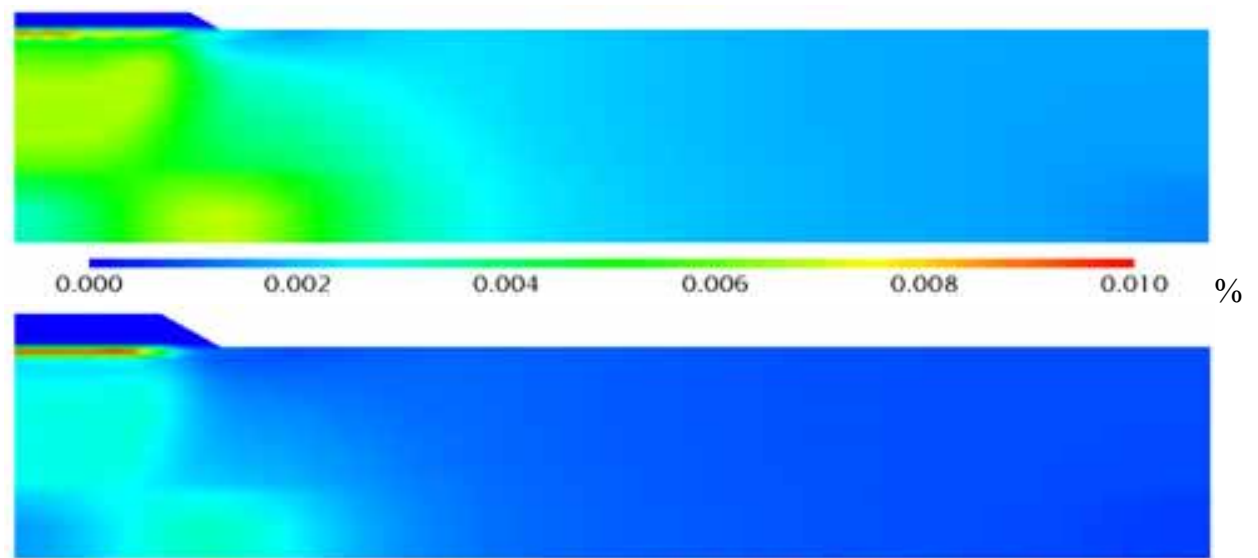

(b)
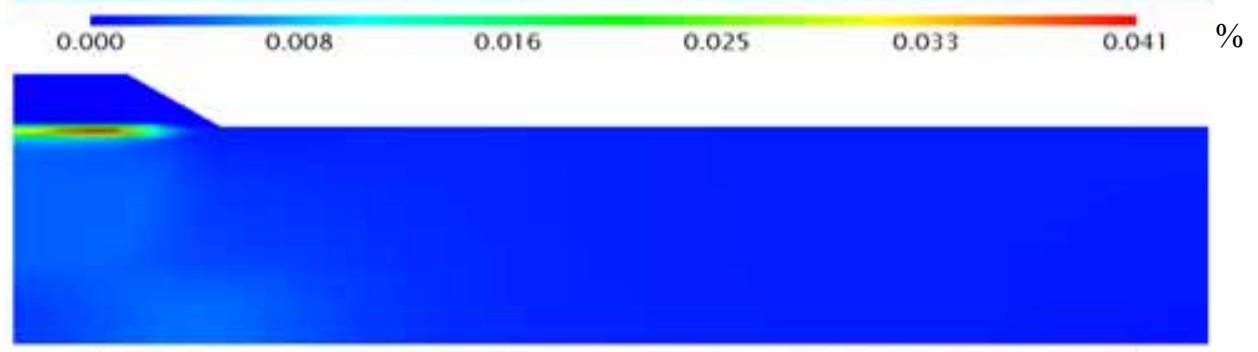

(c)
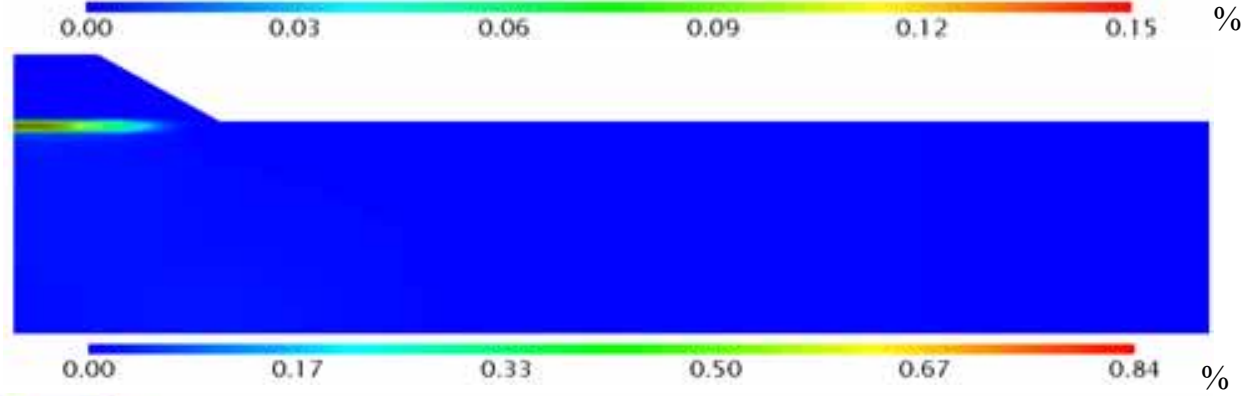

(d)

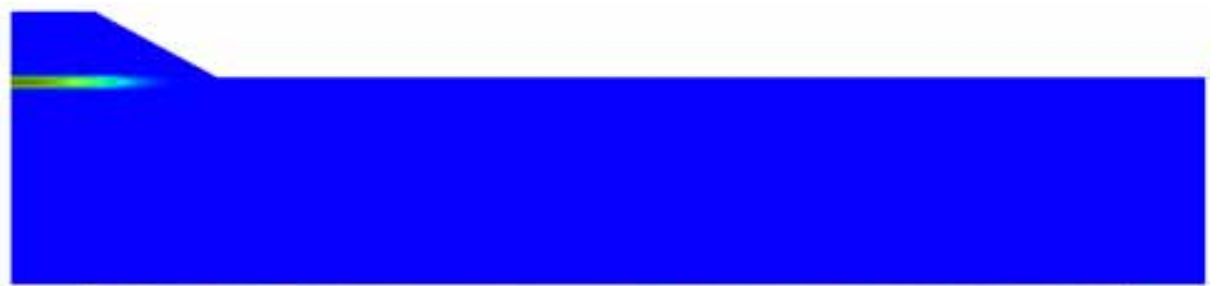

(e)
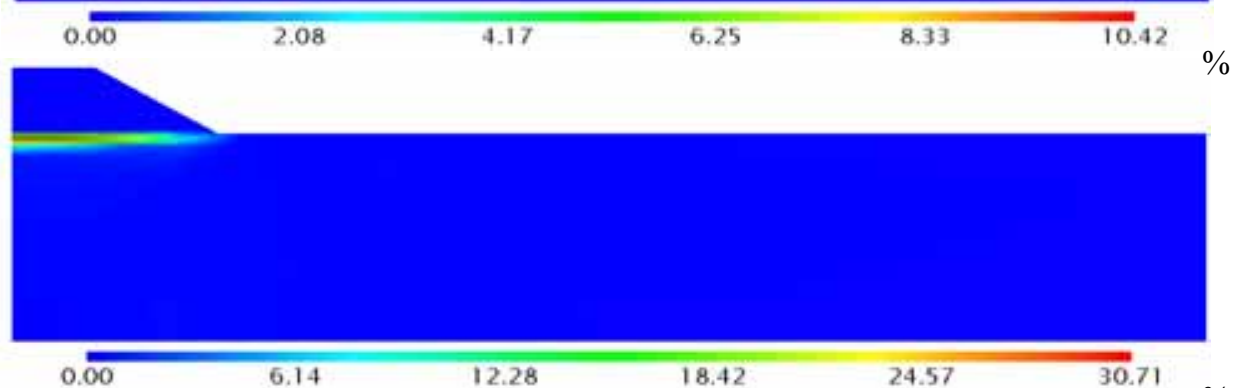

Figure 16. Viscoplastic shear strain contours for Case 3 on various days: (a) 10 days, (b) 20 days, (c) 30 days, (d) 40 days, (e) 100 days, and (f) 1000 days. 
(a)

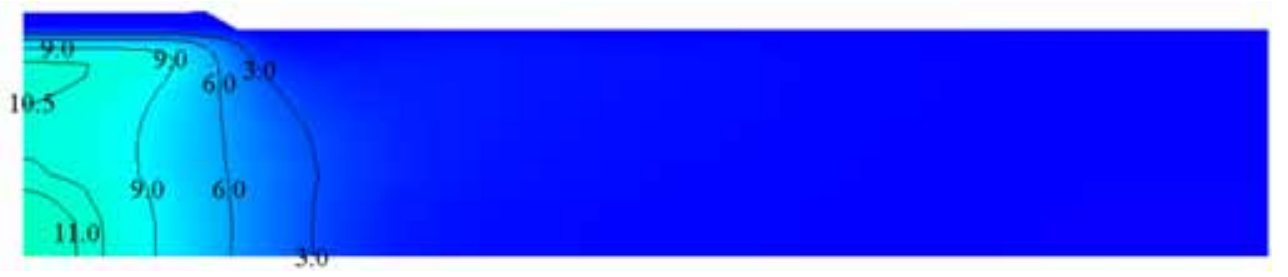

(b)

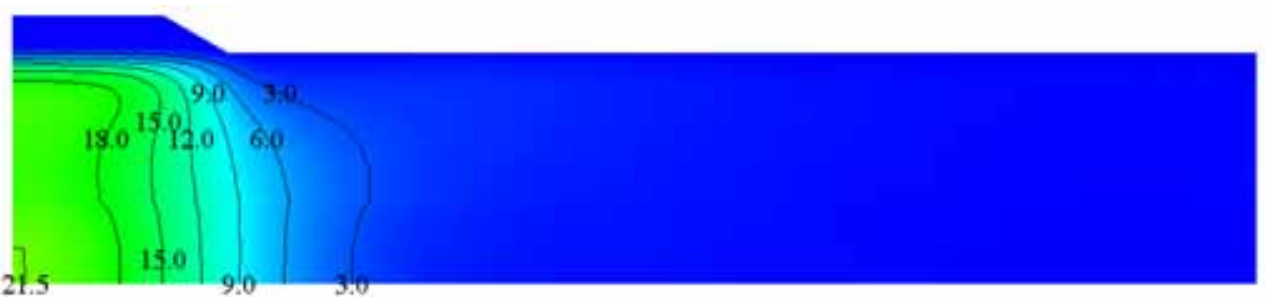

(c)

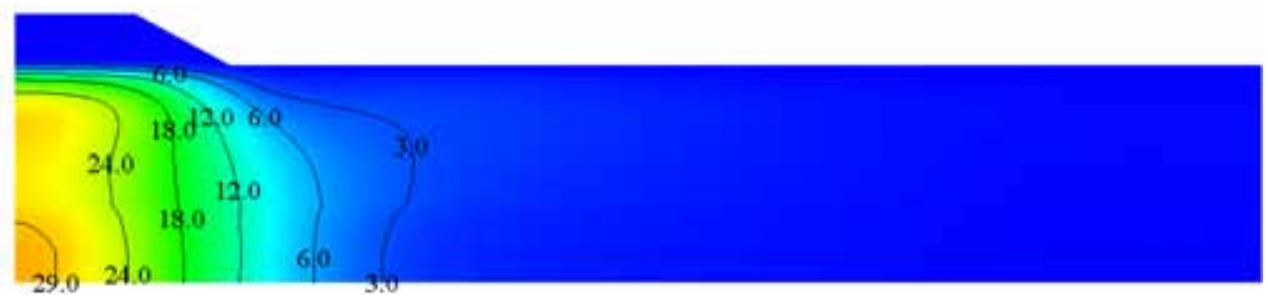

(d)

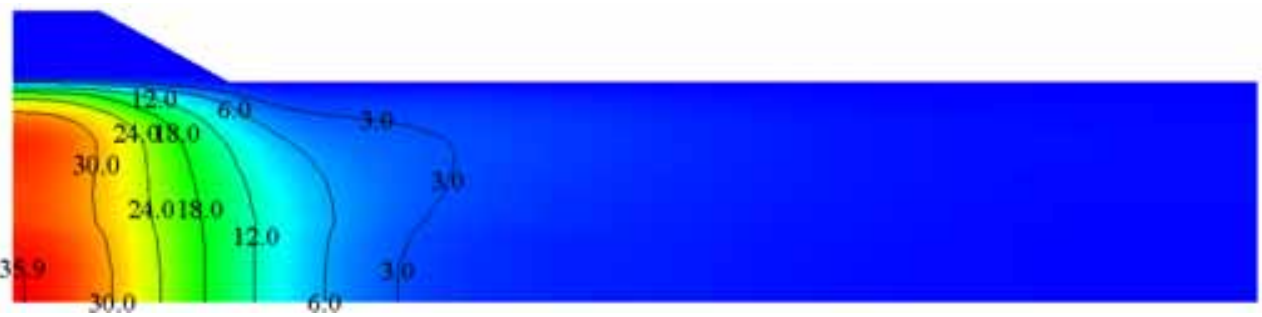

(e)
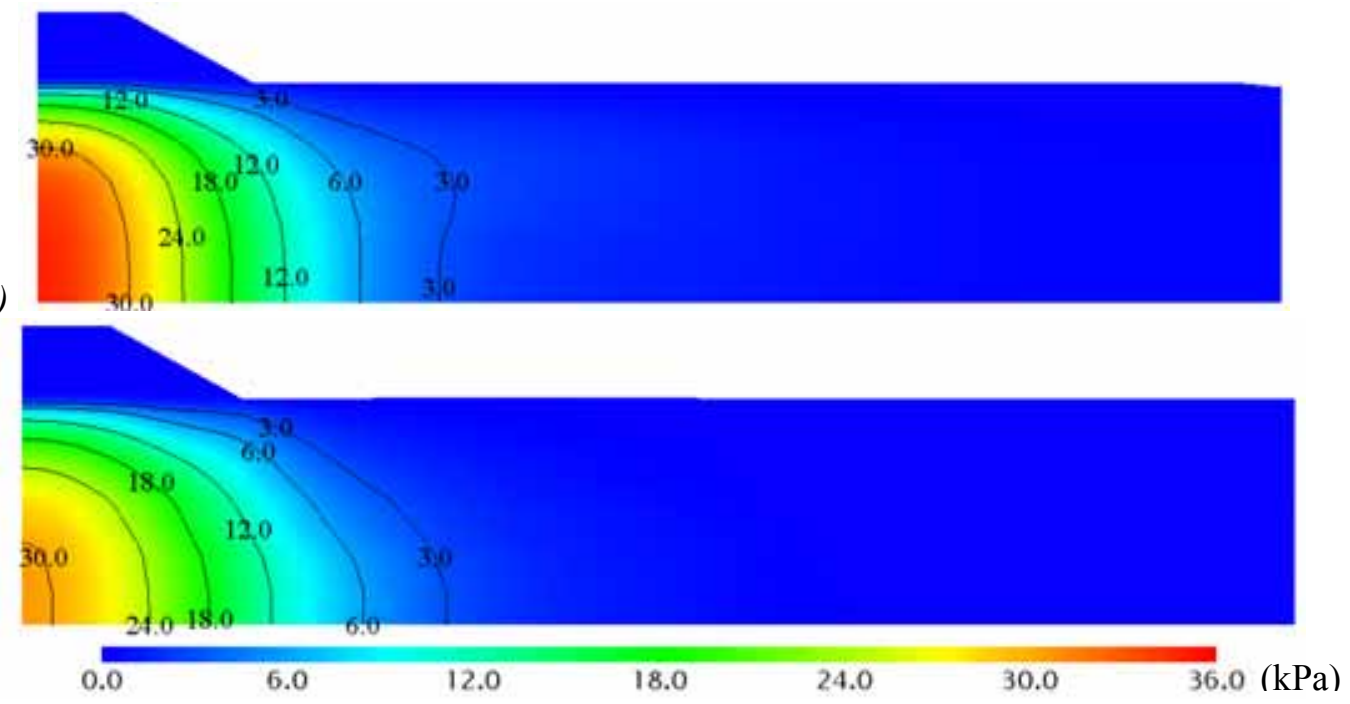

Figure 17. Excess pore water pressure contours for Case 1 on various days: (a) 10 days, (b) 20 days, (c) 30 days, (d) 40 days, (e) 100 days, and (f) 1000 days. 


\section{(a)}

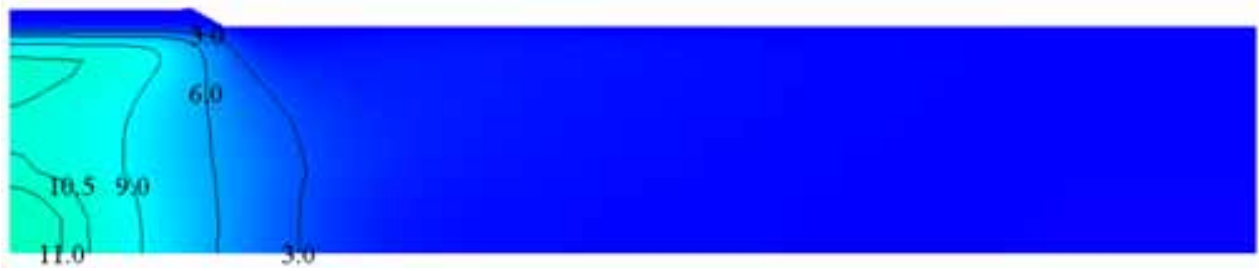

(b) 2

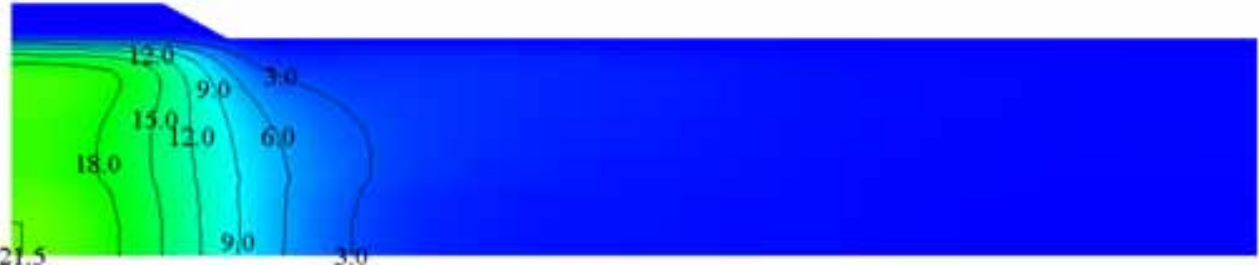

(c)

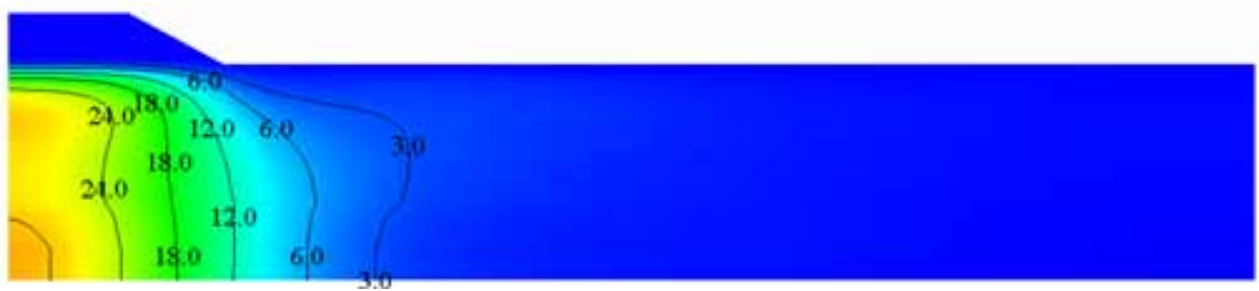

(d)

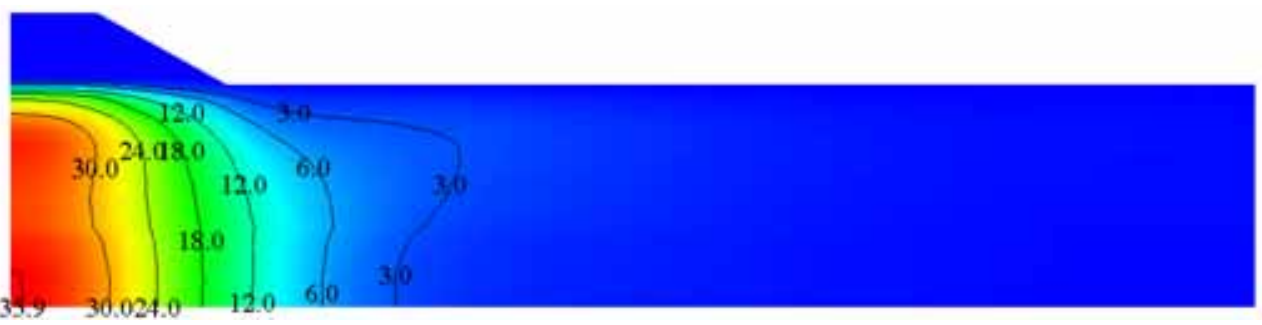

(e)
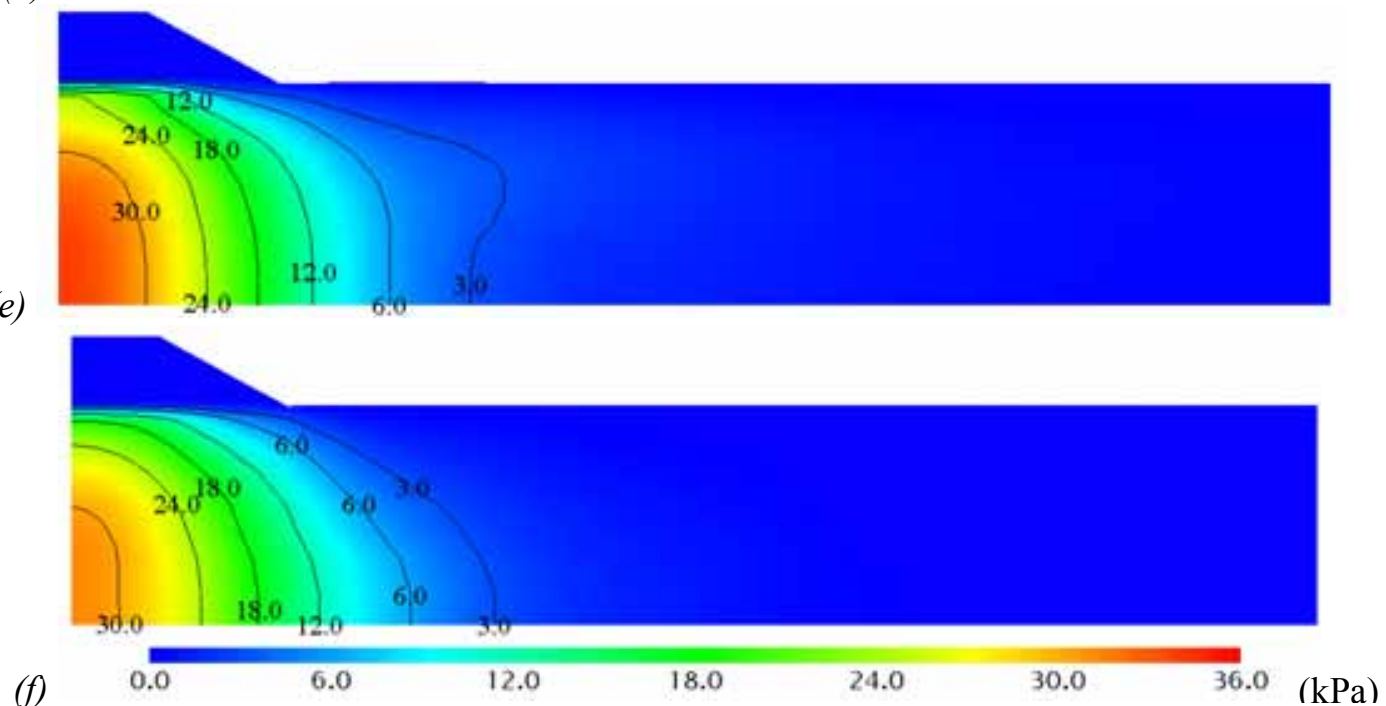

Figure 18. Excess pore water pressure contours for Case 3 on various days: (a) 10 days, (b) 20 days, (c) 30 days, (d) 40 days, (e) 100 days, and (f) 1000 days. 
(a)
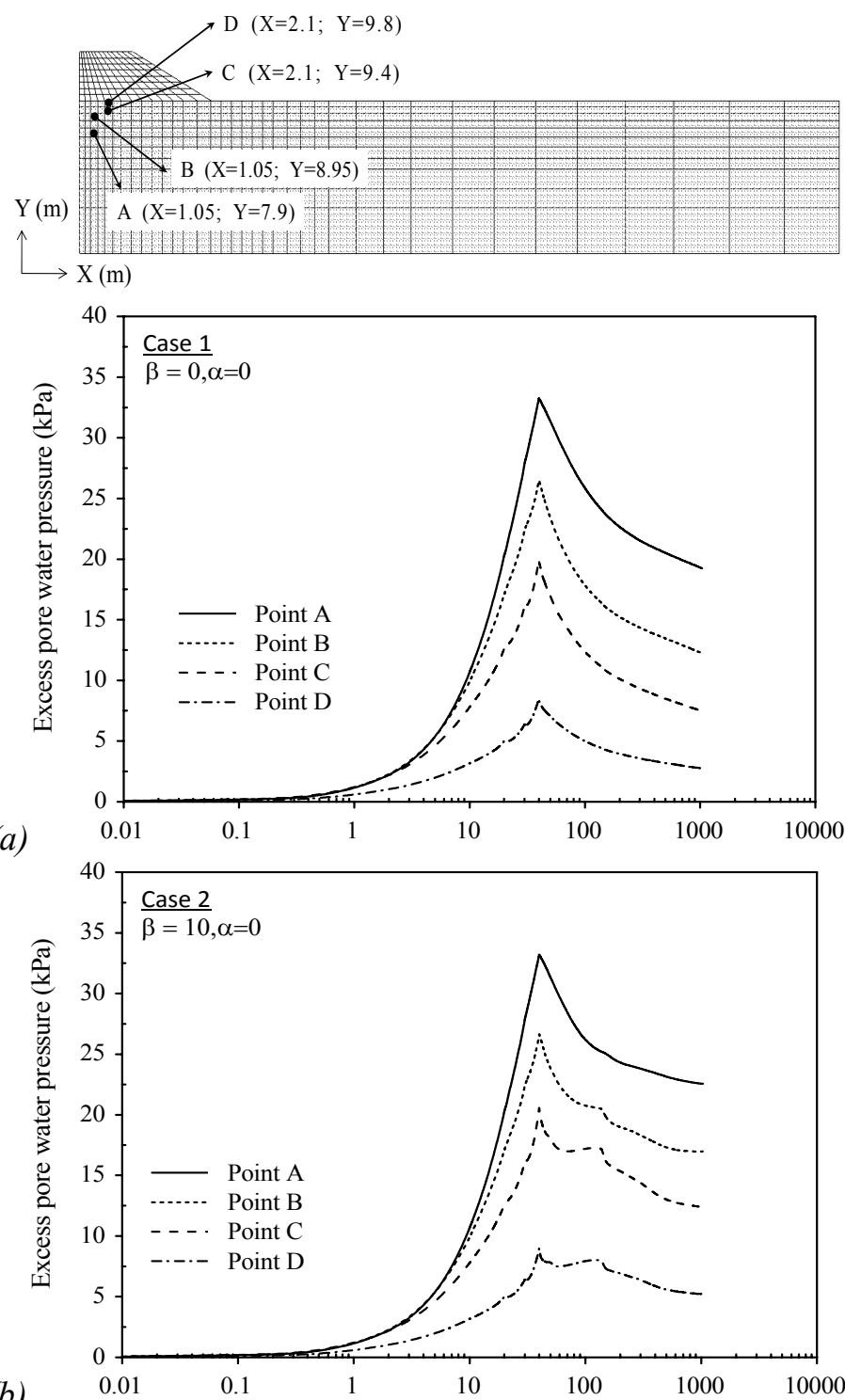

(b)

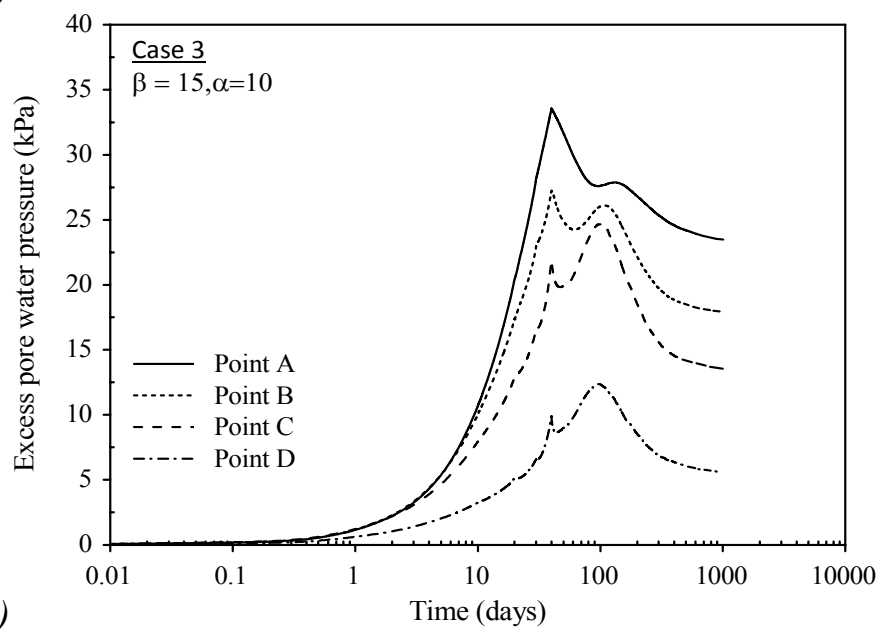

Figure 19. Excess pore water pressure versus time for the different cases. 